\title{
Photopolymerization-based additive manufacturing of ceramics: A systematic review
}

\author{
Sefiu Abolaji RASAKI ${ }^{a, b}$, Dingyu XIONG ${ }^{a}$, Shufeng XIONG ${ }^{a}$, Fang $\mathrm{SU}^{a}$, \\ Muhammad IDREES ${ }^{a}$, Zhangwei $\mathrm{CHEN}^{a, c, *}$ \\ ${ }^{a}$ Additive Manufacturing Institute, Shenzhen University, Shenzhen 518060, China \\ ${ }^{b}$ Institute of Microscale Optoelectronics, Shenzhen University, Shenzhen 518060, China \\ ${ }^{c}$ Guangdong Key Laboratory of Electromagnetic Control and Intelligent Robotics, College of \\ Mechatronics and Control Engineering, Shenzhen University, Shenzhen 518060, China
}

Received: December 30, 2020; Revised: February 2, 2021; Accepted: February 28, 2021

(c) The Author(s) 2021.

\begin{abstract}
Conversion of inorganic-organic frameworks (ceramic precursors and ceramic-polymer mixtures) into solid mass ceramic structures based on photopolymerization process is currently receiving plentiful attention in the field of additive manufacturing (3D printing). Various techniques (e.g., stereolithography, digital light processing, and two-photon polymerization) that are compatible with this strategy have so far been widely investigated. This is due to their cost-viability, flexibility, and ability to design and manufacture complex geometric structures. Different platforms related to these techniques have been developed too, in order to meet up with modern technology demand. Most relevant to this review are the challenges faced by the researchers in using these $3 \mathrm{D}$ printing techniques for the fabrication of ceramic structures. These challenges often range from shape shrinkage, mass loss, poor densification, cracking, weak mechanical performance to undesirable surface roughness of the final ceramic structures. This is due to the brittle nature of ceramic materials. Based on the summary and discussion on the current progress of material-technique correlation available, here we show the significance of material composition and printing processes in addressing these challenges. The use of appropriate solid loading, solvent, and preceramic polymers in forming slurries is suggested as steps in the right direction. Techniques are indicated as another factor playing vital roles and their selection and development are suggested as plausible ways to remove these barriers.
\end{abstract}

Keywords: ceramics; photopolymerization; stereolithography; additive manufacturing; 3D printing; polymer-derived ceramics

\section{Introduction}

Ceramics are the materials with appreciable refractory properties [1]. This has made them relevant for a wide

\footnotetext{
* Corresponding author.

E-mail: chen@szu.edu.cn
}

range of applications which include mechatronics, aerospace, energy industries, bioengineering, construction, and nanotechnology [2]. However, ceramics are materials with high brittleness and hardening [3]. This has limited their applications in the field of advanced technologies where complex geometric structures are needed to be manufactured. Various conventional methods for shaping and tuning solid structures of ceramics have been 
developed to date. Examples are tape casting, dry pressing, casting, and injection molding [4,5]. Despite the effectiveness of those approaches, the use of molds generally inflates the cost of production. More importantly, when it comes to the production of highly complex structures, limitation arises with the use of conventional methods.

Based on the above, research attention has been widely shifted to the use of additive manufacturing (AM) techniques for the fabrication of ceramics. This is due to fact that AM offers (a) highly flexible design of complex structures, (b) integral manufacturing of complex components, (c) material waste minimization, (d) cost-effective production, and (e) short product lead time [6]. It is worth noting that there are different types of AM techniques depending on their energy sources and material requirements [6]. However, from the operation principle and material requirement perspectives, $\mathrm{AM}$ techniques can be generally classified as extrusion and jetting-based, photopolymerization-based, and powder sintering/melting-based techniques. They offer different advantages and benefits as discussed elsewhere [6]. For example, selective laser sintering (SLS) has been recently demonstrated for printing $\mathrm{Al}_{2} \mathrm{O}_{3}$ ceramics with poly-hollow microspheres [7,8]. It was claimed that the technique offers structures with porosity of about $72.41 \%$, making them suitable for catalytic and bio-engineering applications.

Nonetheless, photopolymerization-based additive manufacturing (photopolymerization-based AM) techniques are highly versatile in equipment setup and material requirements, and are able to produce parts with the highest resolution [9]. They are extensively studied and also considered the most promising AM technology in ceramic fabrication and hence become the focus of this review. In this review, a number of major photopolymerization-based AM techniques used for ceramic production are discussed and the relevant working principles, material, and technical requirements are compared in detail. Key challenges and problems associated are also summarized with possible solutions raised.

Photopolymerization-based AM is a series of techniques in which application of light (mostly in ultraviolet range) is used to trigger photochemical reaction and shaping [10]. Among the various types of AM techniques, photopolymerization-based AM is the first AM technique invented dated back to the 1980 s, which was originally used for rapid prototyping of 3D polymeric components [11]. Only since the 1990s, the techniques then were applied in the photopolymerization of ceramicpolymer suspension mixtures into ceramic structures [6]. Examples of the photopolymerization-based AM techniques are stereolithography (SL), digital light processing (DLP), two-photon polymerization (TPP), liquid crystal display (LCD) printing, continuous liquid interface production (CLIP), multi-jet printing (MJP), holographic 3D printing technology, and their derivatives [6,12-14]. These approaches normally offer structure with high feature resolution and surface quality. The photopolymerization-based AM-derived components are often found superior to that of other kinds of AM techniques (e.g., fused deposition modeling (FDM), direct ink writing (DIW), inkjet printing (IJP), selective laser sintering/melting (SLS/SLM), laser engineered net shaping (LENS) in term of structure engineering [15-21]. This is due to the ability of the photopolymerization-based AM techniques to produce materials with high resolution and complex structures.

From the material processing perspective, photopolymerization-based AM techniques are mainly used to process slurries containing photoinitiator and ceramicpolymer matrix as feedstock [6]. The efficiency of most of these approaches (i.e., SL, TPP, DLP, LCD, CLIP, MJP) primarily relies on the photosensitivity of the light-curable polymer matrix and other parameters related to the light intensity of the techniques [22]. Nonetheless, it is worth noting that the printing process plays a vital role too. In general, printing process and material precursor properties (e.g., particle size) may be compromised, and hence enhances the performance of sintered samples [23]. The strategy may aid high mass loading of solid content to avoid mass loss of finished ceramic parts too $[24,25]$.

Despite the advances that have been made by compromising printing parameters, only about $50 \mathrm{vol} \%$ of the ceramic solid content in the slurries is normally found suitable for incorporating the stated properties (e.g., pore reduction, high density, and low shrinkage) into the finished parts [26,27]. In fact, high solid loading ( $\geqslant 50 \mathrm{vol} \%$ ) can decrease flow ability, increase viscosity, cause inhomogeneity, and hence reduce suitability of the slurry for efficient polymerization $[10,28]$. It may hinder workability on the slurries, and hence reduce the fineness of the final structure. Mismatch between the material (slurry) refractive index and light from the $3 \mathrm{D}$ printing techniques is another issue normally causing setbacks. This is because that phenomenon (irradiation-material refractive index mismatch) 
has tendency to reduce curing depth and cause particle coarsening [29]. It may in turn result in the incident light scattering and hence give rise to structure with poor resolution, severe cracks, low mechanical performance, and surface roughness [29]. These are some of the challenges currently faced by researchers in this research area. To address these, for example, Ding et al. $[30,31]$ managed to prepare gray-colored $\mathrm{SiC}$ ceramic slurries suitable for DLP 3D printing by increasing the exposure energy.

Based on the above, several advances have been recently made in order to fabricate parts with complex structures and superior mechanical performance, among which, the use of appropriate material-technique correlation has so far shown interesting results in tackling those eminent setbacks associated with the use of photopolymerization-based AM techniques for the fabrication of ceramics [10,32-35]. The approach has in fact resulted in the fabrication of advanced ceramic structures (Fig. 1), and also led to surge increase in article publication in this research area. Several interesting review articles have been published too, in which working principles, advantages, and usefulness of various photopolymerization-based AM techniques are indicated [6,36-39]. However, among those review articles, only few unraveled the significance of materialprinting process correlation for achieving defect-free structures with complex geometries and superior mechanical properties.

From literature survey, one may note that printing process and precursor property engineering are one of the current research ideas which have shown appreciable results in using photopolymerization-based AM tech- niques for the fabrication of ceramics. Therefore, a timely review of the recent advances made in the field of photopolymerization-based AM is important for further development in this research area, and hence aids the researchers' effort. Based on the above, in this review, the profound understanding of the photopolymerization-based AM techniques is provided. The relevance of these techniques for the fabrication of ceramics is discussed. The main discussions include the following aspects: (1) chemistry and materials behind photopolymerization of different ceramic feedstocks, (2) polymer-derived ceramics that are obtainable through photopolymerization-based AM, (3) different photopolymerization-based AM techniques of relevance to $3 \mathrm{D}$ printed ceramics (in each of the techniques, insight, advantages, and disadvantages are given on the materialtechnique correlation), (4) ceramic functionalities that are derivable via photopolymerization-based AM techniques. The open challenges, way forwards, and prospects associated with the photopolymerization-based AM techniques are discussed too.

\section{Chemistry and material requirement for photopolymerization-based AM}

Photopolymerization is the formation of long chain macromolecules through continuous reaction of small molecules (monomers) in the presence of light exposure [41]. The reaction is normally initiated by the photoexcited reactive species [36]. The reactive species are normally incorporated into the monomer units, and hence cause polymerization reaction in the form of

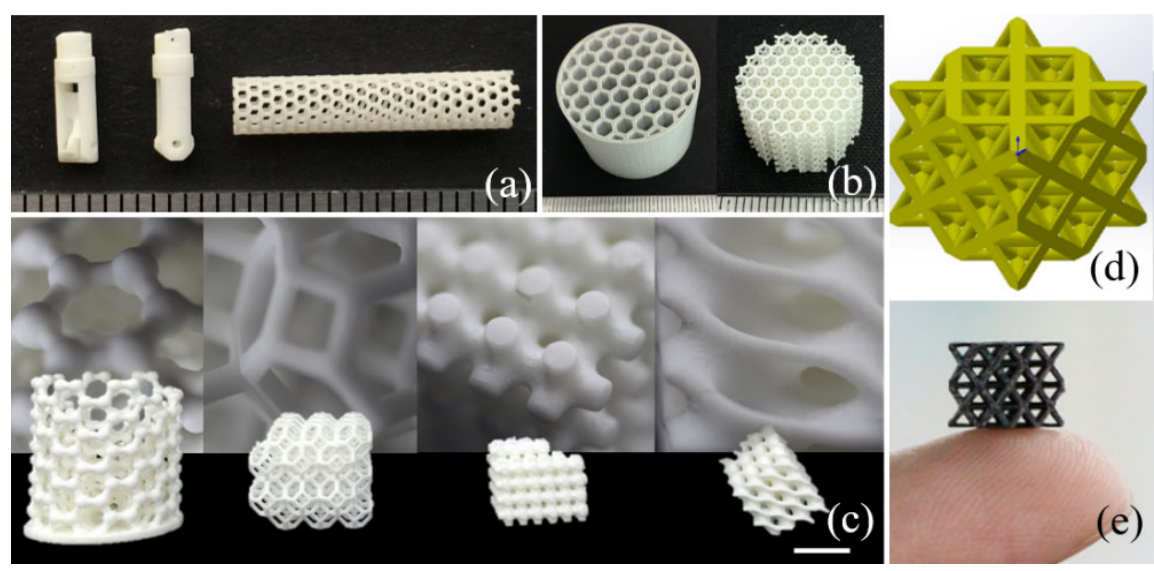

Fig. 1 Examples of ceramic parts prepared via photopolymerization-based AM techniques by Liu and Chen. [40]: (a) precision structural components and porous scaffold, (b) honeycomb lattice structures, (c) different unit cell structures with specifically designed geometries (scale bar $=1 \mathrm{~cm}$ ), (d) CAD model of a lattice structure, and (e) polymer-derived ceramic structure after printing and pyrolysis. Reproduced with permission from Ref. [40], (C) Journal of Materials Engineering 2020. 
long-chain reaction [36]. Generally, photopolymerization rate and efficiency rely on the intensity and wavelength of the light exposed and generated by the AM techniques $[42,43]$. In fact, literature survey suggests that different light sources with wavelength in the range of $200-700 \mathrm{~nm}$ have been so far exploited for the polymerization of the photosensitive liquid resins [44-46]. Although this often depends on the photopolymerization-based AM techniques specified, the property of the photosensitive polymers normally is a key [47]. Specifically, the use of appropriate photoinitiator to generate and propagate reactive species is essential whereas the properties of the monomers and ceramic precursors play vital roles in carrying-out cross-linking reaction process (linear chain reaction of the monomers) [36]. It shows that material-printing process correlation is crucial to the photopolymerization-based AM-derived ceramics with appreciable performances.

Based on the above, different kinds of precursors (both conventional and advanced materials) of relevance to the formation of ceramics through photopolymerization-based AM will be briefly discussed in this section. Here, ceramic precursors that are consisted of powder ceramic-polymer matrix and preceramic polymers are regarded as conventional and advanced ceramic precursors, respectively.

\section{1 Ceramic-polymer matrix}

Ceramic-polymer matrix is regarded as conventional precursor in this review. It is normally in suspension/ slurry forms made up of powdered ceramics, monomers, and photoinitiator [6]. The shaping process in fact involves firstly the photopolymerization of organic contents of the matrix. Then the polymerized content forms interconnected networks to encase or bind the ceramic particles in the slurry matrix to become selfsustaining solid parts. The examples of the powdered ceramics which have been so far used to form con- ventional ceramic precursor are alumina $\left(\mathrm{Al}_{2} \mathrm{O}_{3}\right)$, zirconia $\left(\mathrm{ZrO}_{2}\right)$, silica $\left(\mathrm{SiO}_{2}\right)$, hydroxyapatite (HA), cordierite, zirconate titanate oxides (PZT), silica carbide ( $\mathrm{SiC}$ ), and silicon nitride $\left(\mathrm{Si}_{3} \mathrm{~N}_{4}\right)[6,36,48,49]$, to name a few. The powdered ceramics of about $40-50 \mathrm{vol} \%$ in the ceramic-polymer matrix are usually recommended to maintain suitable viscosity and to avoid too much shrinkage in the final ceramic structures [36].

It is worth noting that ceramics themselves are highly brittle and non-photosensitive in nature [36]. This often worsens the processing of the conventional precursors during the $3 \mathrm{D}$ printing especially by using photopolymerization-based AM techniques. Nonetheless, the various research advances which have been so far conducted have shown that ceramic-polymer matrix can be easily printed and shaped into complex structures via photopolymerization-based AM techniques depending on the formulation approaches [29,50,51]. Specifically, monomer/oligomer-photoinitiator-powdered ceramic combination and correlation are of high significance for forming efficient and photocurable precursors for ceramics $[29,50,51]$. It makes the use of monomer/ oligomer and photoinitiator crucial for the forming of ceramic-polymer matrix as precursors in the field of photopolymerization-based AM. The typical steps involve for the formulation of ceramic-polymer matrix, and its use for 3D printing of ceramics via photopolymerizationbased AM techniques is illustrated in Fig. 2. As shown in Fig. 2, each of the constituents of the ceramicpolymer matrix has a significant role during the photopolymerization process as discussed subsequent sections.

\subsubsection{Photoinitiator}

Photoinitiators (PIs) are the photo-reactive species [45]. They are normally added to the liquid resins (ceramicpolymer matrix) as an initiator of photopolymerization process [52]. Specifically, PIs are molecules that can easily absorb photon of light, and hence form reactive

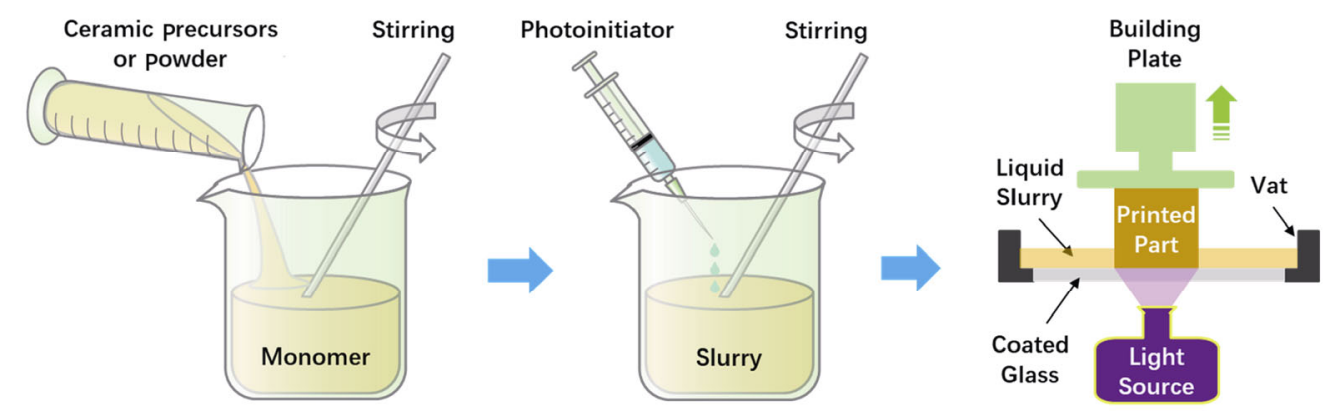

Fig. 2 Schematic illustration of steps involved in the photopolymerization-based AM of ceramic parts. 
species [52]. The reactive species will then attack the functional group of a monomer in the liquid resin, decomposes the alkyl functional group (i.e., $\mathrm{C}-\mathrm{C}$ ), and hence generates more reactive species [53,54]. This normally multiplies the reactive species in the reaction system, and therefore increases the reaction chain [36]. It will result in the formation of polymer structures. The polymer formation will then give rise to the covalent bond between the adjacent functional groups with bonding strength stronger than that of monomers [36]. It will generate solid structures (printed body) consisting of the binder and ceramics [47]. The printed (green) body may have different chemical and structural properties when compared to that of liquid resins (i.e., the ceramic-polymer matrix) to indicate structural transformation (i.e., photopolymerization) [52].

Photoinitiator can be categorized into free-radical and cationic reactive species [55]. The free-radical PI produces free-radical after absorbing photon of light [56]. Free-radical PIs are useful for the photopolymerization of liquid resins consisting of acrylates and methacrylate monomers (i.e., free-radical photopolymerization) [56]. However, cationic reactive photoinitiators are the PIs producing acid after absorbing photon of light (e.g., UV light) [55]. They are useful for the photopolymerization of liquid resins with functional groups of epoxides, vinyl ethers, propenyl ethers, siloxanes, cyclic acetals, and furfural [57]. All of these show the significance of PI for the photopolymerization of conventional ceramic precursors into ceramics via photopolymerization-based AM techniques.

\subsubsection{Monomer}

Monomers are organic molecules which are responsible for binding the ceramic particles during the photopolymerization process [46]. It constitutes the major part of the ceramic-polymer precursors. It also forms large portion of the printed or green ceramic structures [36]. Monomers are essentially necessary to be thermally volatile in order to drive their easy removal during the post-thermal treatment (debinding) of the printed structures at temperature of about $500-550{ }^{\circ} \mathrm{C}$ $[36,58,59]$. It suggests that analysis of thermogravimetric property of the monomer is essential before being employed as binder. The analysis may aid sintering (heating at much higher temperature of $>1000{ }^{\circ} \mathrm{C}$ ) of the final structure too, since complete removal of the binders will give rise to defect-free and highly dense structures [58,59]. Similarly, it is important that monomer has high solubility to make it serves as reactive diluents for ceramic particles [46,60]. Monomers have to be engineered to generate photosensitive liquid resins with low viscosity. This will in turn result in the formation of slurry that has rheological properties (e.g., flow-ability, photosensitivity, and viscosity) matching well with different kinds of photopolymerization-based AM techniques. The typical examples of monomers that has rheological property suitable for the various types of photopolymerization-based AM are acrylates, methacrylate epoxides, vinyl ethers, propenyl ethers, siloxanes, cyclic acetals, and furfural [47,56,57].

In the field of photopolymerization-based AM, oligomers and monomers have similar functions; however, the former (oligomers) are consisted of two or more structural units of the later (monomers) [45]. It thus makes oligomers to exhibit larger molecular structures and higher viscosity. It may be otherwise referred to as prepolymers or macromonomers. Oligomers have also been found relevant as binders for photopolymerization of ceramic particles [36]. However, they are less attractive when compared to the monomers. This is because they have inferior workability due to its high viscosity [36]. This normally reduces light penetration through the liquid resins, and hence hinders the curing depth [36]. In fact, most work is being conducted using monomers. Brief but coincided discuss of photopolymerization of monomers is therefore given in the subsequent section.

(1) Chemical mechanism for photopolymerization of monomer

Acrylate based resins (e.g., methylacrylate) with $\mathrm{RH}\left(\mathrm{R}=\right.$ aryl group or $\left.\mathrm{CH}_{3}\right)$ are the monomers which have been widely used for $3 \mathrm{D}$ printing of ceramic parts [61]. The monomers are highly reactive in the presence of suitable photoinitiator under UV light $[62,63]$. However, it is worth noting that other factors such as temperature, atmosphere, light irradiation rate, and photoinitiator type may influence the monomer polymerization efficiency too [63]. For example, temperature in the range of $70-90{ }^{\circ} \mathrm{C}$, and oxygen inhibition atmosphere has been reported as factors favored photopolymerization of acrylatebased resins [63]. The role of photoinitiator is crucial as well. In fact, the type of photoinitiator is normally used to classify photopolymerization process into cation/anionic and radical [64].

Based on the existing literature, radical photopolymerization is the most common one [64], and the 
formation of its photoinitiating systems is normally caused by carbon-carbon bond cleavage of PIs (e.g., aromatic carbonyl compounds). The typical mechanism involved is illustrated in step 1 of Fig. 3. This is normally regarded as Type I photoinitiating process [63]. In that mechanism, benzoyl radical is the primary photoinitiator or radical $\left(\mathrm{PI}^{*}\right)$ for propagating the polymerization of monomers [64]. However, the secondary (alkyl) radical may influence the photopolymerization process too, depending on its concentration [64]. The common examples of Type I photoinitiators are benzyl dimethyl ketals, a-amino ketones, acylphosphine oxides, hydroxyalkylphenones, and benzoin ether derivatives $[64,65]$.

It is worth noting that Type II photoinitiating system has been widely reported too. The chemical mechanism involves formation of aromatic ketone coupled with main radical (i.e., radical of hydrogen donor) for propagating the photopolymerization of monomers [64]. The mechanism is illustrated in step 2 of Fig. 3. During the photopolymerization process, the aromatic ketone radical will be disappeared through chemical coupling reaction after being used by the hydrogen donor (RH) [64]. This approach can be also referred to as hydrogen abstraction mechanism $[64,65]$. Aromatic diketones, benzophenone, phenylglyoxalates, thioxanthones, methylphenylglyoxylate, and camphorquinone are common Type II photoinitiators whereas amines, ethers, and alcohols are used as hydrogen donors [66,67]. Hydrogen abstraction from monomer or another photoinitiator has also been reported as shown in steps 3 and 4 of Scheme 1 [63].

One should note that when excessive amount of PI is used, the efficiency of photopolymerization may be

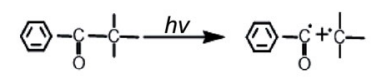

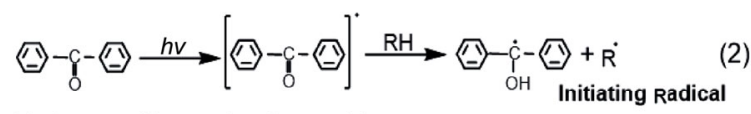

Hydrogen Abstraction from a Monomer

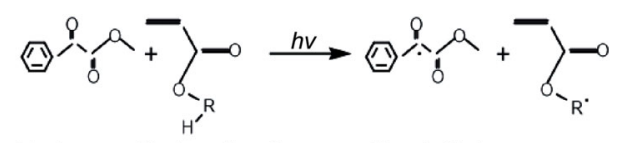

Hydrogen Abstraction from Another Initiator

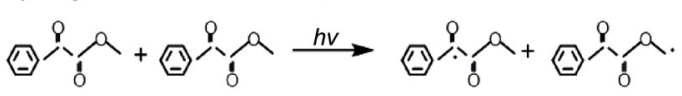

Fig. 3 Chemical mechanism for the formation of photoinitiating system [63]. " $h v$ " represents UV light, and "." represents radical. Reproduced with permission from Ref. [63], (C) The Society of Polymer Science, Japan 2019. compromised. For example, Sanai et al. [63] recently demonstrated the use of methyl phenylglyoxylate (MP) as photoinitiator for photopolymerization of acrylate-based resin. In their research, initiation and determination pathways were proposed using Types I and II processes. It was realized that acrylate-based resins could exhibit both intermolecular and intramolecular hydrogen abstraction as shown in Fig. 4. Specifically, when MP initiates polymerization of acrylates, and abstracts hydrogen from the monomer particularly at its alkyl group, efficient photopolymerization process is derived [63]. This is due to the direct formation of acryloyl groups which enables high crosslinking ability. It in turn results in substantial amount of gelation (steps 1 and 2 of Fig. 4). This suggests that when appropriate amount of PI (particularly $<5 \%$ ) is used, efficient photopolymerization of ceramicpolymer matrix may be obtained $[68,69]$. Furthermore, when MP abstracts hydrogen from another MP (i.e., due to excessive PI), benzoylcarbonyloxy group will be formed [63]. It may in turn give rise to dead polymers as shown steps 3 and 4 of Fig. 4 . All of these show that efficient photopolymerization of ceramicpolymer matrix relies on precursor formulation.

In summary, conventional precursors (ceramicpolymer matrix) for photopolymerization-based AM can be formed using powdered ceramics, organic monomers (e.g., acrylate and epoxy), and PIs. Other materials like fillers (carbon, silica glass, etc.) can be added too, in order to increase the mechanical properties of the final ceramics. The ceramic-polymer matrix with about $40-50$ vol\% of the ceramic powder has been found useful for the fabrication of highly dense ceramic structures. That composition can be used to avoid excessive shrinkage and delamination during post-thermal treatment, and hence gives rise to final ceramic structures with appreciable performance.

\section{2 Advanced preceramic precursors}

In this review, the polymers that do not involve ceramicpolymer matrix and can be directly photopolymerized and pyrolyzed into ceramics are regarded as advanced precursors (i.e., preceramic precursors (PCPs)). These polymers are normally prepared from monomers containing silicon [70]. They are commonly used to fabricate polymer-derived ceramics (PDCs) via photopolymerization-based AM techniques [70,71]. The selection and properties of the preceramic precursors are known to normally influence the performance and 


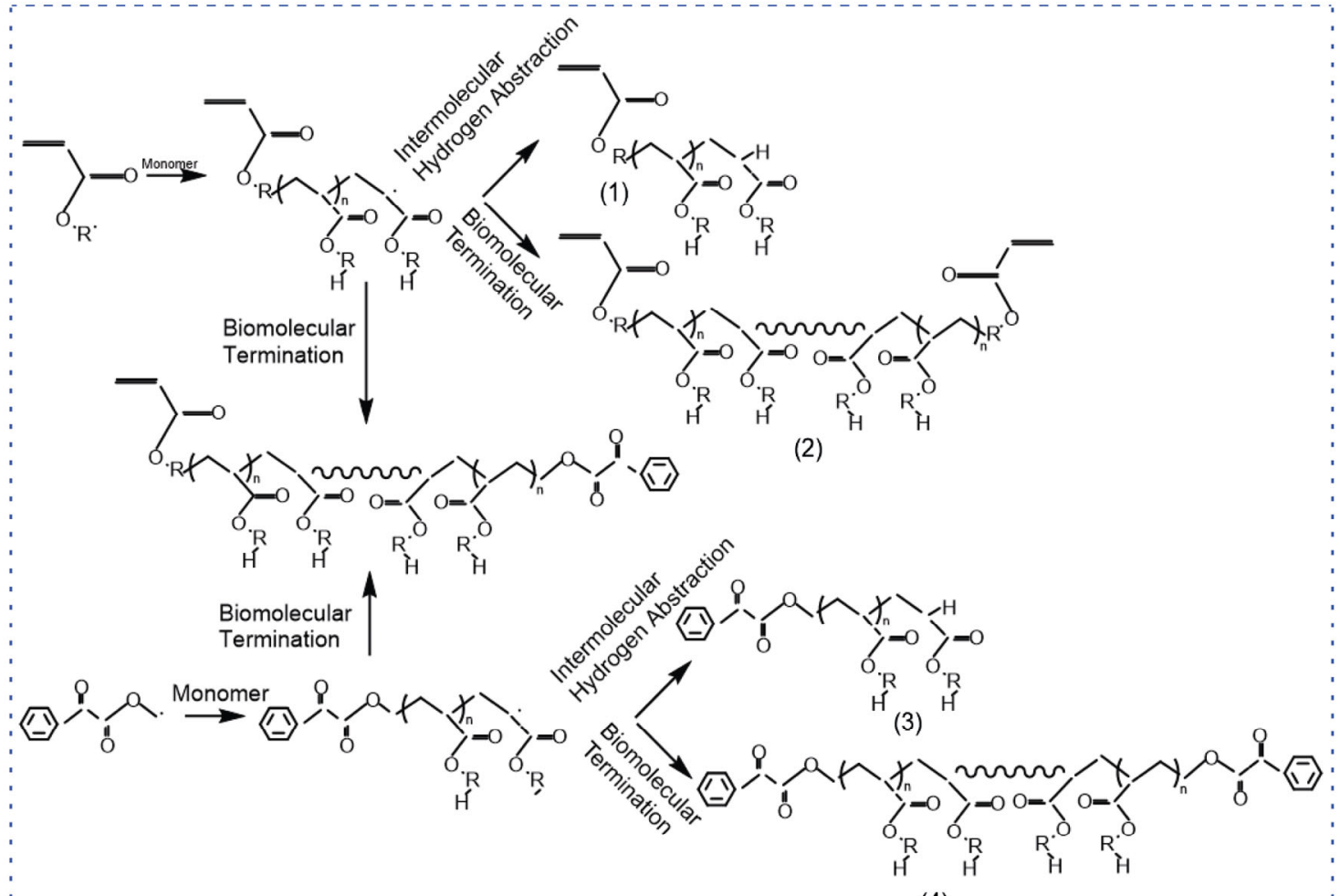

(4)

Fig. 4 Chemical mechanism for the formation of photoinitiating system [63]. "." represents radical, and "n" represent number of polymerization steps. Reproduced with permission from Ref. [63], (c) The Society of Polymer Science, Japan 2019.

properties of the final ceramics (i.e., PDCs) as discussed in Section 3. Examples of these polymers are polycarbosilane, polysilazane, and polysiloxane compounds. It is worth noting that these polymers generally exhibit different photopolymerization mechanisms and hence give rise to PDCs with varying degree of performance [72,73]. Specifically, preparation of the photosensitive organosilicon polymers is the primary challenge before the subsequent photopolymerization. For instance, addition of acrylate or methacrylate to organosilicon polymers (i.e., preceramic precursors) is normally used to enhance carbon-carbon cross-linking ability of precursors, particularly during photopolymerization via stereolithographic technique [73]. However, that approach normally suffers from volume shrinkage, and it is highly sensitive to oxygen contaminant [73]. As a result of that, the use of thiol-ene free radical reaction (i.e., click reaction) has thus become popular. This is a reaction where photopolymerization is based on cross-linking reaction between sulfurhydrogen and carbon-carbon group within preceramic precursors. The reaction can give rise to highly yield ceramics, fast photopolymerization rate, little or no volumetric shrinkage, and it is insensitive to oxygen and water contaminants [74].

In addition, it is well known that preceramic polymers with high-molecular weight, high solubility, and high cross-linking ability have possibility of producing PDCs with appreciable performance [70]. The bonding between the $\mathrm{Si}$ and carbon, nitrogen, or oxygen on the organosilicon polymer plays a vital role too [70]. It shows that the properties of the preceramic precursors are one of the key factors determining the photopolymerization efficiency. Therefore, this section will be used to discuss various preceramic precursors (advanced precursors) of relevance to the photopolymerizationbased AM of ceramics.

\subsubsection{Polycarbosilane}

Polycarbosilane is organosilicon useful for the fabrication of the PDCs containing $\mathrm{Si}-\mathrm{C}$ bonds. Polycarbosilane is often prepared using cross coupling reaction between molecules of polysilanes (e.g., polydimethylsilane, polydimethylmethylphenylsilane, and polydimethyl-methylsilane), and hence generates multiple carbon-carbon bonds [73]. The photopolymerization process of the polycarbosilane into $\mathrm{SiC}$ is illustrated in Fig. 5. 


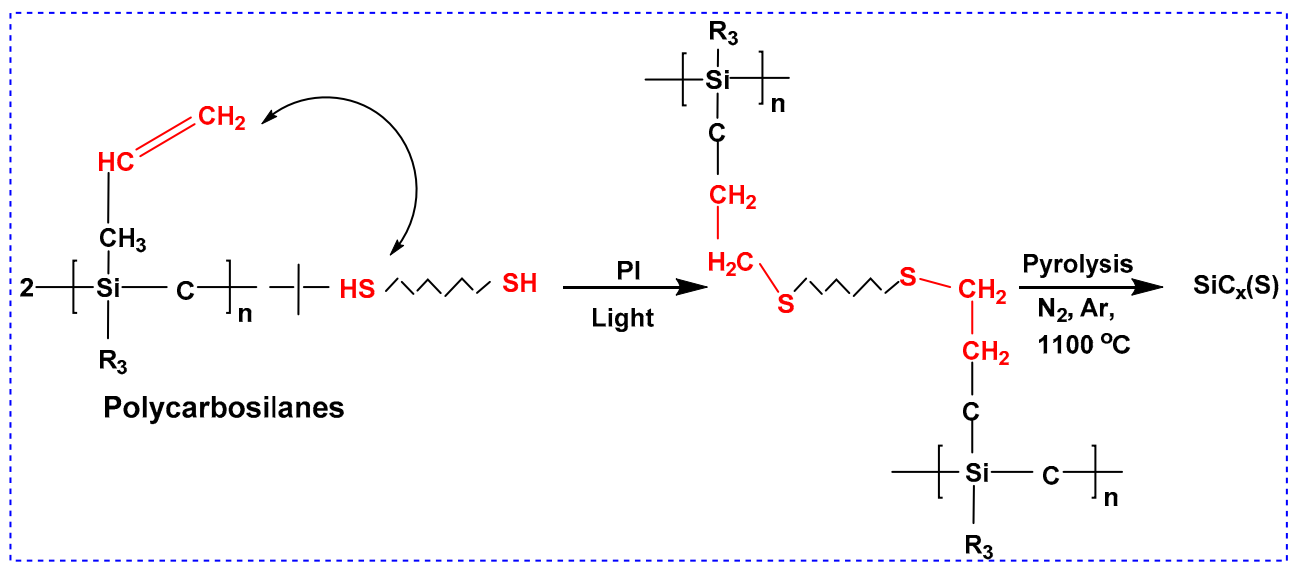

Fig. 5 Illustration of photopolymerization of polycarbosilane into PDCs. Reproduced with permission from Ref. [73], C Elsevier B.V. 2019.

Polysilane (e.g., polydimethyl-methylsilane) normally exhibits similar photopolymerization process when it is being used directly for the $\mathrm{SiC}$ preparation $[70,75,76]$. Post-thermal treatment (i.e., pyrolysis at about 1000$1100{ }^{\circ} \mathrm{C}$ ) of the green PDCs obtained from the polycarbosilane or directly from the polysilane is crucial in order to obtain dense PDC structures [73]. It normally enhances $\mathrm{S}-\mathrm{C}$ cross-linking reaction. However, it is worth noting that the PDCs $(\mathrm{SiC})$ derived from the photopolymerization of the polycarbosilane normally exhibits superior performance in term of high ceramic yield, density, and tensile strength [77]. This is because polycarbosilane contains high molecular weight of carbon and superior cross-linking ability [70,78]. It shows that the use of polycarbosilane as preceramic precursor benefitted the $\mathrm{SiC}$ production regardless of the photopolymerization-based AM techniques [73].

Its photopolymerization process may give rise to stable and defect-free thermoset ceramic structures, hence preserving the final shape after pyrolysis [73]. This performance is somehow better than that of $\mathrm{SiOC} / \mathrm{SiCN}$ and $\mathrm{SiC}$ and other ceramics $\left(\alpha-\mathrm{Al}_{2} \mathrm{O}_{3}\right)$ prepared from other precursors and/or fabricated via different routes (e.g., powder-based approaches) $[79,80]$.

In summary, polycarbosilane is useful preceramic precursor for the fabrication of $\mathrm{SiOC}$ or $\mathrm{SiC}$ ceramics via photopolymerization-based AM techniques. Similarly, polysilane can be directly polymerized into $\mathrm{SiC}$ too. However, it is worth noting that polymers with high molecular weight and carbon-carbon cross-linking ability favor high yield of final ceramics. It has the tendency to improve the density and tensile strength too.

\subsubsection{Polysilazane}

Polysilazane is another type of the advanced precursors for ceramic 3D printing. It is mainly used for the preparation of nitrogen-containing PDCs. The examples of such PDCs that can be obtained from the polysilazane preceramic precursors are silicon nitride $\left(\mathrm{Si}_{3} \mathrm{~N}_{4}\right)$, silicon carbonitride $(\mathrm{SiCN}), \mathrm{Si}_{3} \mathrm{~N}_{4}$, and silicon oxynitide (SiON) $[81,82]$. Polyborosilazane is a chemical family of the polysilazane, and it is mostly relevant for the preparation of silicon borocarbonitride ( $\mathrm{SiBCN})$ [83]. The photopolymerization process of the polysilazane preceramic precursors is shown in Fig. 6. The polymers have general molecular structure of $\left[-\mathrm{R}_{1} \mathrm{R}_{2} \mathrm{Si}-\mathrm{N}=\right]_{n}$ where $\mathrm{R}$ and $n$ are the alkyl group and the number of polymerized chains, respectively [73].

It has been reported that polysilazane can be efficiently polymerized into $\mathrm{SiCN}$ even in the presence of ordinary visible light irradiation [84,85]. For instance, a liquid mixture consisting of polysilane, photoinitiator (PI, e.g., 2,2-dimethoxy-2-phenyl acetophenone) has been photopolymerized into PDCs in the presence of ordinary visible light irradiation with wavelength of $>$ $400 \mathrm{~nm}$ [84]. It has also been found that the use of polysilazane for the fabrication of $\mathrm{SiCN}$ structures using AM techniques can give rise to materials with appreciable thermal resistance [84]. This is due to the high carbon-carbon cross-linking ability coupled with nitrogen diffusion into the $\mathrm{C}-\mathrm{C}$, and hence reinforces the bonding structure. All of these have thus proven suitability and the efficient photopolymerization of the polysilazane for AM of PDCs particularly SiCN.

In summary, polysilazane is a good preceramic precursor for the fabrication of nitrogen containing PDCs. It has efficient photopolymerization process due to the high $\mathrm{C}-\mathrm{C}$ cross-linking ability. However, pyrolysis of the green PDCs under nitrogen atmosphere at a 


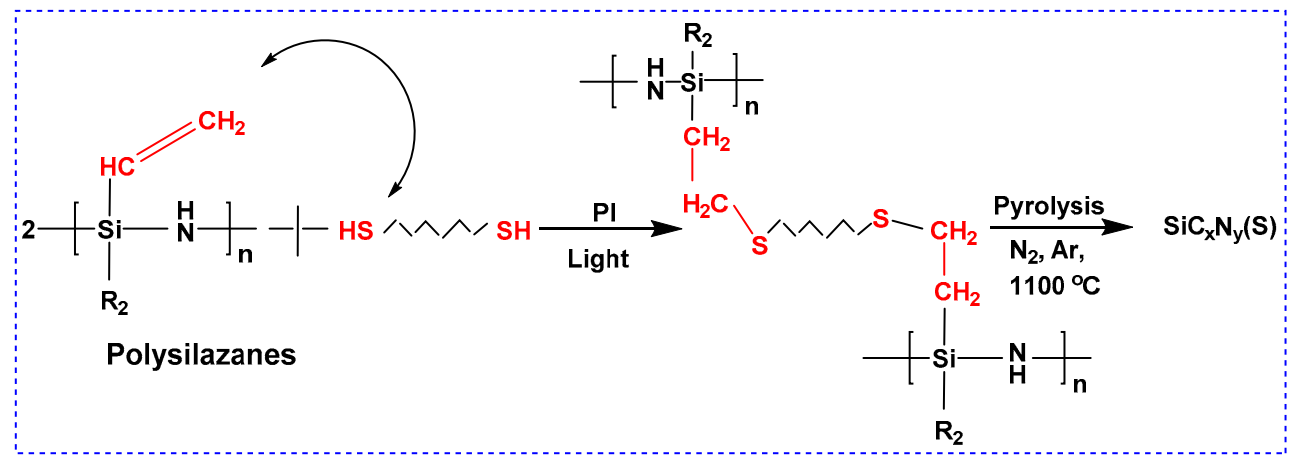

Fig. 6 Illustration of photopolymerization of polysilazane into PDCs. Reproduced with permission from Ref. [73], C Elsevier B.V. 2019.

temperature range of $1000-1100{ }^{\circ} \mathrm{C}$ can aid formation of SiCN material with highly dense structures. The approach normally favors tensile strength of the final PDCs too [86].

\subsubsection{Polysiloxane}

Polysiloxane is mostly used for the formation of silicon oxycarbide (SiOC) [70,87]. Among the preceramic precursors which have been exploited for the PDCs printing via photopolymerization-based AM techniques, polysiloxane is the only oxygen containing polymer. This makes polysiloxane mostly suitable for the fabrication of $\mathrm{SiOC}$ ceramics. It can be used for the printing and fabrication of ceramics with appreciable mechanical and thermal resistance too $[88,89]$. This is because polysiloxane has low inter-molecular force on its silicon-oxygen-silicon skeleton, and it has high cross-linking ability too [70,87]. This normally aids high yield of the final SiOC ceramics. The preceramic polymer is normally prepared using sol-gel methods (i.e., hydrolysis and condensation of silicon alkoxide) [90-92]. The material photopolymerization process is illustrated in Fig. 7.

The common example of the polysiloxane is polysil- sesquioxane found relevant for 3D printing of $\mathrm{SiOC}$ nanoceramics [93]. Generally, the 3D printed PDCs from polysiloxane precursor normally have carbon content of $>20 \mathrm{wt} \%$, favorable to high thermal and chemical stability of the final ceramics [93]. Similarly, it has been demonstrated that secondary element intercalation $(\mathrm{Al}, \mathrm{Ti}$, and $\mathrm{B})$ into the polysiloxane is possible by using sol-gel preparatory approach $[93,94]$. This may enable the fabrication of PDCs with structure phase like SiCNO, SiBCN, SiBCO, SiAlCN, and SiAlCO [93]. However, the high viscosity of the polysiloxane containing secondary elements is a major challenge hindering its implementation for photopolymerization-based AM techniques. It is a research area that needs more attention.

\section{PDCs obtainable through photopolymeri- zation-based AM}

3D printed polymer-derived ceramics (PDCs) can be obtained in two-step approaches which are 3D printing of the green polymers, and the pyrolysis of printed polymers into the final PDCs [95]. The precursors

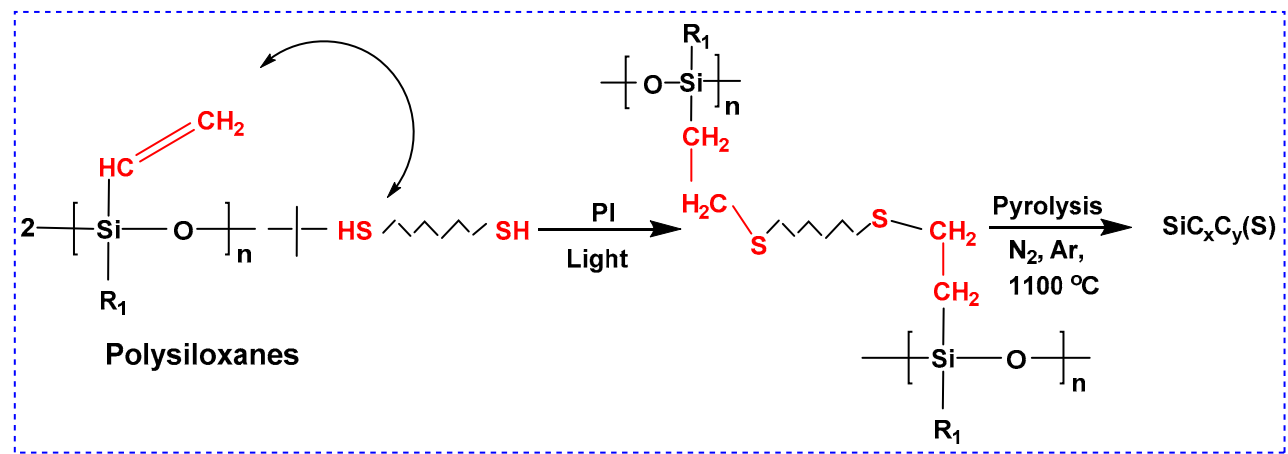

Fig. 7 Illustration of photopolymerization of polysiloxane into SiOC ceramics. Reproduced with permission from Ref. [73], C Elsevier B.V. 2019. 
(mainly polymers) are normally printed based on computer designed (CAD) models [95]. The printed polymers are essentially necessary to be pyrolyzed at temperature of $\geqslant 1000{ }^{\circ} \mathrm{C}$ under inert atmospheres in order to generate stable and dense structures [96]. It is worth noting that PDCs can be sub-categorized into binary, ternary, and quaternary as detailed in the subsequent sub-sections. This depends on the phase composition of the final ceramics. However, it has been widely demonstrated that the selection of precursor plays a vital role in the formation of particular phases [70]. In short, various forms of PDCs including complex phases have been recently fabricated through the use of photopolymerization-based AM techniques [70].

\section{1 Binary polymer derived ceramics}

These are PDCs consisting of two elements. The common examples of these materials are $\mathrm{SiC}$ and $\mathrm{Si}_{3} \mathrm{~N}_{4}$. When compared to other AM techniques, fabrication of these ceramics ( $\mathrm{SiC}$ and $\mathrm{Si}_{3} \mathrm{~N}_{4}$ ) from the preceramic precursors using photopolymerization-based AM often enables good shaping process, and it can also reduce time- and energy-consumption.

$\mathrm{SiC}$ can be derived from polycarbosilane [70]. The pyrolysis of the printed polycarbosilane at temperature of $>1000{ }^{\circ} \mathrm{C}$ can result in SiC structures with appreciable mechanical strength and chemical stability [78].
It has been reported that modification of the polycarbosilane is essential to obtain $\mathrm{SiC}$ with appreciable properties. For instance, the mixture of polycarbosilane and epoxy containing molecules (e.g., epoxytetrahydrofuran) has been used to fabricate highly porous $\mathrm{SiC}$ at the expense of low density [97]. It shows that incorporation of epoxide into the polycarbosilane backbone is useful for the fabrication of 3D-printed $\mathrm{SiC}$ scaffolds for bioengineering application. Similarly, polystyrene has been used to modify polycarbosilane in which $\mathrm{SiC} / \mathrm{SiO}_{2}$ core shell is obtained after pyrolyzing the photopolymerized sample at $1200{ }^{\circ} \mathrm{C}$ [98]. All of these show that preceramic precursor properties can be compromised in order to prepare binary $\mathrm{SiC}$ with remarkable performance.

Nonetheless, it is worth mentioning that pyrolysis temperature may influence the performance of final ceramic structures too [78]. It has in fact been discovered that the use of high pyrolytic temperature $\left(\geqslant 1000{ }^{\circ} \mathrm{C}\right)$ can lead to substantial phase transformation of the preceramic resins into $\mathrm{SiC}$ ceramic structures without clogging [70,78,99]. Specifically, Li et al. [99] have revealed that there is possibility of having amorphous and crystalline phases at temperature of $600-800{ }^{\circ} \mathrm{C}$, and $1000{ }^{\circ} \mathrm{C}$ (Fig. 8), respectively. It shows that ceramic parts with appreciable properties can only be obtained by pyrolyzing printed preceramic resins at temperature of $\geqslant 1000{ }^{\circ} \mathrm{C}$ (Fig. 8 (c)) [99].

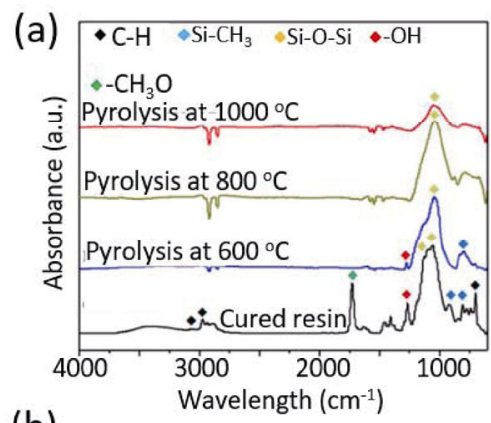

(c)
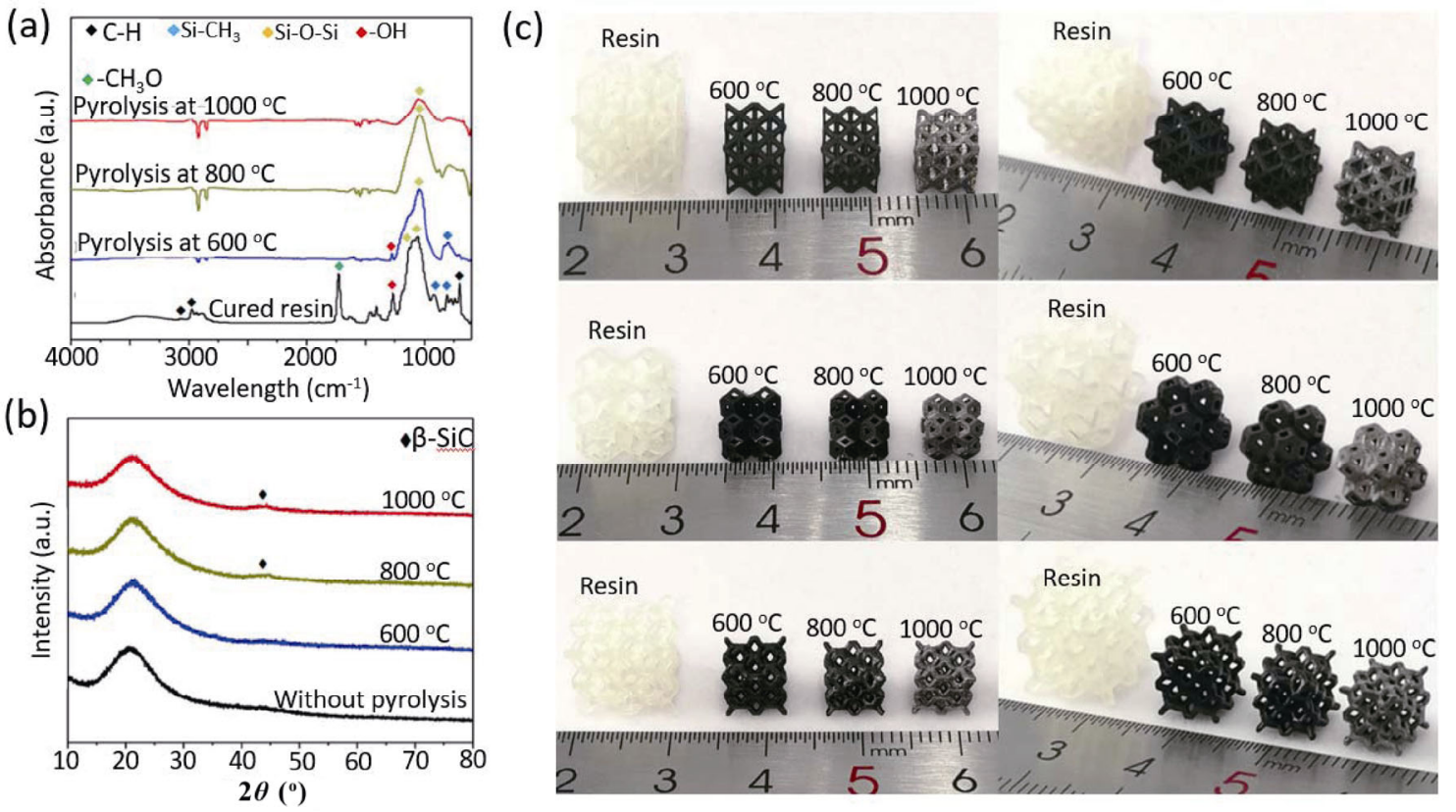

Fig. 8 (a) FT-IR spectra of the preceramic precursors pyrolyzed at $600-1000{ }^{\circ} \mathrm{C}$, (b) XRD patterns of preceramic precursors at $600-1000{ }^{\circ} \mathrm{C}$. (c) Photos of front and side views of the printed polymer and pyrolyzed SiOC ceramic components with different structures. Reproduced with permission from Ref. [99], (C) The Author(s) 2020. 
Similarly, $\mathrm{Si}_{3} \mathrm{~N}_{4}$ has also been reported using carbonfree polysilazane as precursor via DLP [100]. The yield of the $\mathrm{Si}_{3} \mathrm{~N}_{4}$ was normally improved by pyrolyzing the printed samples under $\mathrm{N}_{2}$ atmosphere at temperature of $>1200{ }^{\circ} \mathrm{C}$ [70,101-103]. However, only few reports are currently available on the $3 \mathrm{D}$ printed $\mathrm{Si}_{3} \mathrm{~N}_{4}$ using preceramic precursors. This is due to the fact that polysilazane (the common precursor for the $\mathrm{Si}_{3} \mathrm{~N}_{4}$ ) contains carbon, and hence the formation of $\mathrm{SiCN}$ is usually unavoidable. It is a challenge causing setbacks for the preparation of pure form of $\mathrm{Si}_{3} \mathrm{~N}_{4}$ using photopolymerization-based AM techniques.

In summary, photopolymerization of preceramic precursors such as polycarbosilane and carbon-free polysilazane using $\mathrm{AM}$ techniques can give rise to $\mathrm{SiC}$ and $\mathrm{Si}_{3} \mathrm{~N}_{4}$, respectively. The performance and properties of the final ceramic have been so far improved by compromising the preceramic properties. The use of appropriate post-thermal treatment (i.e., pyrolysis at temperature range of $1000-1500{ }^{\circ} \mathrm{C}$ ) is essential too. All of these have been demonstrated as factors determining the mechanical strength, chemical stability, and porosity of the final components $[104,105]$. However, it is worth noting that the pure form of these ceramics, particularly $\mathrm{Si}_{3} \mathrm{~N}_{4}$ is difficult to prepare due to the lack of suitable precursors. $\mathrm{SiC}$ is prone to surface oxidation, and thus is less popular when compared to other types of PDCs. These are areas where further research studies are needed.

\section{2 Ternary polymer derived ceramics}

These are ceramics containing three elements. The common examples are $\mathrm{SiCN}, \mathrm{SiCO}, \mathrm{SiOC}$, and $\mathrm{SiON}$. They are often derived using polysiloxane, polycarbosilane, and polysilazane. It is worth noting that among the ternary ceramics, SiOC is extremely popular due to its strong oxidation and corrosion resistance ability $[106,107]$. It has appreciable chemical stability, and thermal durability too $[104,108,109]$. Eckel et al. [71] reported photopolymerization of polysilozane compound into SiOC ceramics. In their work, the UV-curable preceramic polymer (polysilozane) was mixed with photoinitiator, and hence polymerized the mixture (Fig. 9(a)). The polymerized samples were then pyrolyzed at $1000{ }^{\circ} \mathrm{C}$ (Fig. 9(b)). The approach gave rise to various forms of defect-free cellular structures (Figs. 9(c)-9(f)).

Similarly, de Hazan and Penner [104] used polycarbosilane polymer as precursor for the fabrication of SiOC ceramics. The photopolymerization of the preceramic polymer was performed in the presence of acrylate resin using SL technique. The materials exhibit non-porous surface which aids the material flexibility and its engineering towards different geometric shapes. Nonetheless, the SiOC ceramics with high porous surface have also been fabricated using different types of photopolymerization-based AM techniques [110-113]. It shows that properties of SiOC derived via photopolymerization-based AM techniques can be engineered towards catalytic and bioengineering applications.

In brief, the properties of the PDCs especially the ternary forms can be easily tailored towards particular application using photopolymerization-based AM techniques. However, precursor selection plays a vital

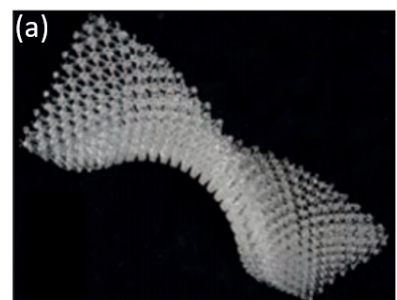

(d)

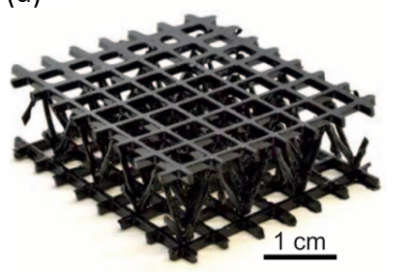

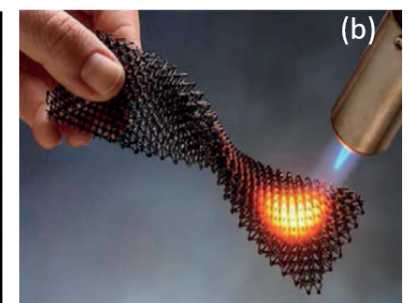

(e)

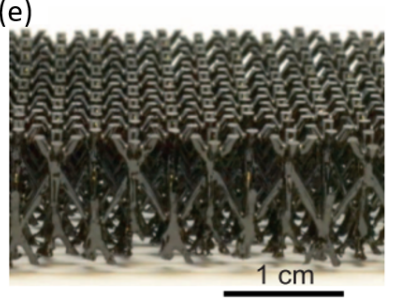

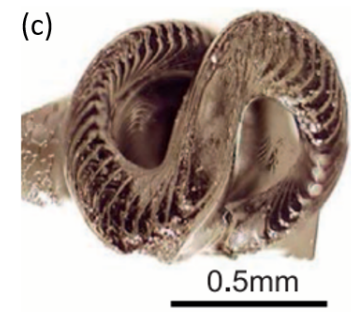

(f)

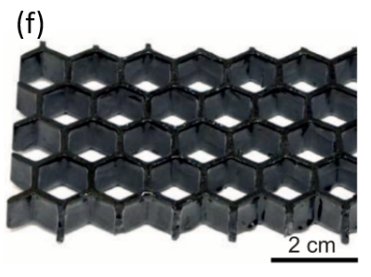

Fig. 9 (a) Printed preceramic polymer, and (b) pyrolyzed ceramic of SiOC. Other complex geometric structures: (c) cork screw, (d, e) micro-lattices, and (f) honeycomb of the SiOC. Reproduced with permission from Ref. [71], (C) American Association for the Advancement of Science 2016. 
role on the emerging properties of the final PDCs. This is the research area where more attention is needed in order to fabricate ternary PDCs with appreciable property for advanced technological applications.

\section{3 Complex polymer derived ceramics}

These are PDCs with more than three elements. They can be referred to as quaternary PDCs. Typical examples are silicon borocarbonitride $(\mathrm{SiBCN})$, and silicon aluminocarbonitride (SiAlCN). Although only few reports are currently available on this material, they are normally prepared using polyborosilazane and aluminosilazane. It may be worth noting that the performance and yield of quaternary/complex ceramic is normally superior to that of other ceramics. Example of quaternary ceramics recently reported through photopolymerizationbased $\mathrm{AM}$ is $\mathrm{SiBCN}$ where polyborosilazane and photosensitive acrylate were used as precursors [83]. It was claimed that the SiBCN ceramic exhibited appreciable thermal stability and resistance in air at high temperature of about $1500{ }^{\circ} \mathrm{C}$ [83]. Furthermore, the use of polyborosilazane as precursor is favorable for the high yield (58\%-78\%) of the SiBCN ceramic [114]. When polyborosilazane is used as precursor, the ceramic yield is about 1.7 times higher than that of polysilazane [115].

Similarly, it has been found that $\mathrm{SiBCN}$ can be obtained by polymerizing a mixture of UV-curable borazine ring and acrylate $[116,117]$. The borosilazane precursor can give rise to SIBCN ceramics with defect-free and highly dense structures [116,117]. It was also found that the use of the borosilazane precursor can aid photopolymerization process in which a complete reaction may be obtained within 5 min of UV irradiation.

\section{Photopolymerization-based AM techniques currently used for ceramic fabrication}

Photopolymerization-based AM techniques are the 3D printing techniques suitable for the transformation of polymers or their matrix into ceramics $[36,118]$. The techniques can be used to fabricate ceramics with complex geometric structures. They are the approaches using light-activated spatial and temporal control for irreversible polymerization of monomers into polymers $[36,118]$. It can successfully transform liquid resins containing ceramic particles into solid mass of ceramicpolymer composite via photoreaction. Through the photopolymerization process, the techniques can be used to shape liquid resins into solids with complex geometric structures. Once again, the common and recent examples of the photopolymerization-based AM techniques are stereolithography (SL), digital light processing (DLP), two photon polymerization, liquid crystal display (LCD) printing, continuous liquid interface production (CLIP), and multi-jet printing (MJP).

From the material requirement and operation perspective, each of the photopolymerization-based AM techniques differs. They offer different kinds of benefits, and the associated setbacks are different too. For example the two major prominent examples of the photopolymerization-based AM techniques are SL and DLP, and they have different light sources. Specifically, SL uses light spot with wavelength of about $355 \mathrm{~nm}$, and it is useful for the photopolymerization of nonsemiconducting materials [62,119]. In contrast, DLP uses digital micromirror device (DMD) with wavelength of about $405 \mathrm{~nm}$, and it is mainly used for the photopolymerization of semiconducting materials [9]. Similarly, LCD is a recent technique with strike resemblance to the DLP; however, the two techniques have different light intensity [120]. In short, DLP and LCD are designed for different printing processes. Therefore, this section will be used to discuss different 3D printing techniques of relevance for the photopolymerization of both conventional and advanced ceramic precursors. For each technique, emphasis will be placed on the printing process-material correlation, and the current advances made in solving the eminent challenges associated with the techniques.

\section{1 Stereolithography (SL)}

Stereolithography is one of the earliest AM techniques [6]. The photopolymerization is carried out by directly exposing the UV-light to the resin or monomer tank via top-down (i.e., the curing light is above the resin) or bottom-up (the curing light is beneath the resin) fashions $[10,121]$. This normally gives rise to solidification of the liquid resin. A layer by layer patterning of the printed material can be done by controlling the movement of the laser beam [29]. It is worth noting that SL is the best approach for printing large size models due to its wide range of laser beam movement (along XYZ direction) as illustrated in Fig. 10(a) [36]. 

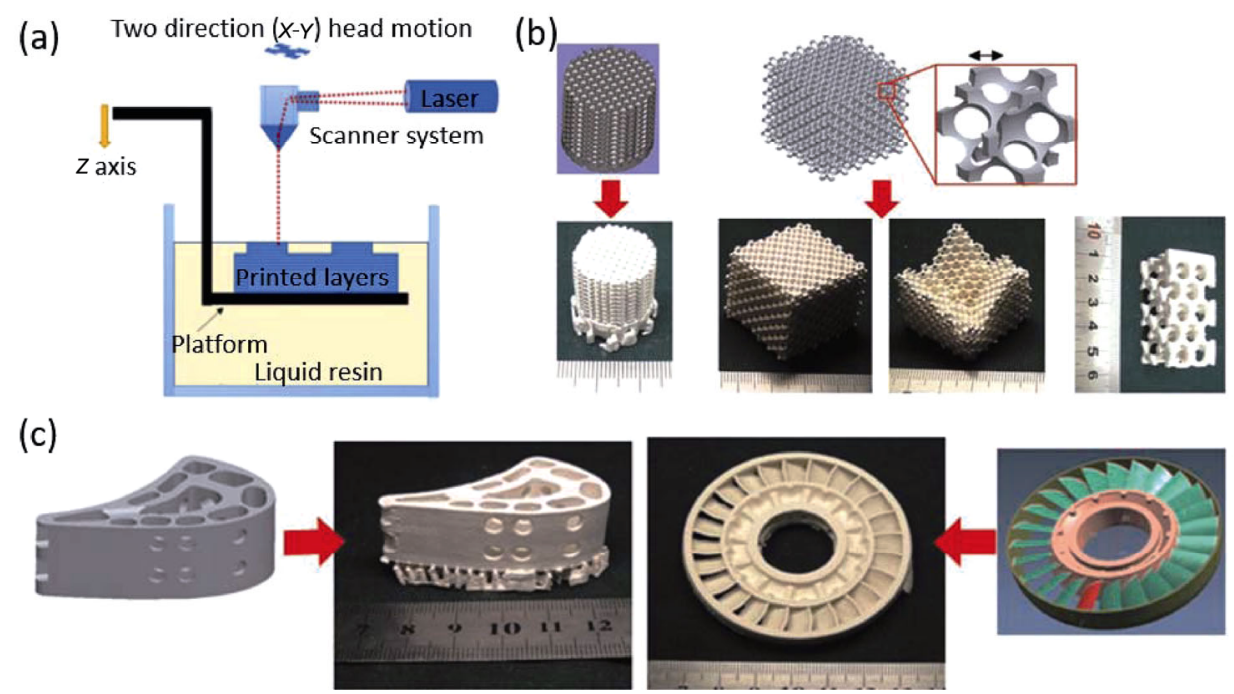

Fig. 10 (a) Schematic illustration of SL working principle. Ceramic samples fabricated using SL: (b) porous functional components, (c) structural parts and casting molds. Reproduced with permission from Ref. [13]. (C) SAGE Publications 2012.

Although, SL has slow printing rate due to long range movement of its laser beam, it has the ability to produce structures with wide range of sizes (e.g., dental, toys, molds, automotive, aerospace field, and so on).

The typical examples of ceramics fabricated through this approach were reported by Chen et al. [13] in 2012. In that research, effect of printing parameters (i.e., laser scanning speed, layer thickness setup, hatch spacing, and laser spot compensation) was investigated on the performance of the final ceramic parts. After compromising several parameters, it was discovered that hatch spacing, laser scanning speed, and sliced layer thickness of $0.15 \mathrm{~mm}, 1400 \mathrm{~mm} / \mathrm{s}, 0.15 \mathrm{~mm}$, and $0.35 \mathrm{~mm}$ respectively favored the performance of final silica-based ceramics (Figs. 10(b) and 10(c)). Effect of sintering temperature in the range of $1000-1400{ }^{\circ} \mathrm{C}$ was investigated too, and found that optimum performance with bending strength of $\sim 10 \mathrm{MPa}$ could be obtained at $1000{ }^{\circ} \mathrm{C}$ at heating rate of $150{ }^{\circ} \mathrm{C} / \mathrm{h}$ for $1 \mathrm{~h}$. However, a higher temperature of $1200{ }^{\circ} \mathrm{C}$ was found suitable for incorporating porosity of $35 \%$ into the porous functional parts of the ceramics (Fig. 10(b)).

Before the above works were conducted, the same research group investigated the amount of silica content suitable for forming suspension to realize ceramic structures with appreciable performance [122]. Silica content of about $50 \mathrm{vol} \%$ was used to form suspension containing acrylamide (monomer), methylenebisacrylamide as cross-linker, and glycerol as solvent. The commercial silica materials were found having a refractive index, density, and mean particle sizes of
$1.50,2.65 \mathrm{~g} / \mathrm{cm}^{3}$, and $1.553-9.343 \mu \mathrm{m}$, respectively. It was discovered that the volume and mean diameter of the silica particles influenced properties of the final ceramic parts. Specifically, by increasing the concentration of monomer the curing depth of the printed sample could be enhanced. This is because silica particles possess a higher refractive index. It thus indicates that high loading (e.g., above $50 \mathrm{vol} \%$ ) of the silica content may reduce curing depth due to its high refractive index. High ratio of monomer to solid content in a slurry can thus benefit curing depth, and hence reduce curing duration.

In addition, Tian et al. [123] have revealed efficient post-treatment for the SL-derived ceramic structures which successfully minimized linear shrinkage. It was discovered that with the use of vacuum-freezing drying process the linear shrinkage of the green structures obtained via SL could be minimized to approximately $2.0 \%$. It shows that the mass loss and cracks can be somehow avoided during sintering process by using vacuum-freezing drying for the green structures. All of these indicate that the precursor properties (i.e., slurry rheological property), printing process as well as post-thermal treatment play vital roles during the use of SL for ceramic fabrication. It suggests that the use of appropriate material-printing process correlation is crucial for the fabrication of $3 \mathrm{D}$ printed ceramics with appreciable properties.

In addition to the above, several PDCs have been reported to be printed via stereolithography approach. Examples are $\mathrm{SiOC}, \mathrm{SiC}$, and $\mathrm{SiBCN}[71,104,108]$. It 
is worth mentioning that with the use of SL for the fabrication of PDCs, the selection of preceramic precursors determines the properties of the final PDC parts.

Specifically, the composition of the preceramic polymer normally influences the yield, properties, and performance of the final PDCs. For example, it has been proven that siloxane with $\mathrm{Si}-\mathrm{O}-\mathrm{Si}$ backbone is mainly useful for the preparation of SiOC [71]. Similarly, the preceramic polymers consisting of siloxane and silazane mixture have been used to prepare SiOCN using SL technique [71]. It shows that silazane with $\mathrm{Si}-\mathrm{N}-\mathrm{Si}$ backbone is mainly used to prepare $\mathrm{SiCN}$ and SiOCN ceramics. In addition, the yield of the final PDCs can be substantially improved using preceramics with high carbon-carbon crosslinking density [71]. In that regard, infiltration of crosslinking agents (e.g., divinyl benzene) into the preceramic precursor has been found helpful [71]. It has the possibility to increase the carbon content in the final PDCs, and hence enhances the material performance. Incorporation of other kinds of elements (e.g., B, Zr, $\mathrm{Fe}, \mathrm{Co}, \mathrm{Ni}, \mathrm{Cu}, \mathrm{Pd}, \mathrm{Pt}$ ) into the preceramic precursors to tailor final PDCs towards particular applications (thermal membrane, magnetic and catalytic application) has also been found possible [124]. In short, different kinds of the ceramics fabricated through SL by compromising precursor formulation are shown in Table 1. Therein, the performance of the final ceramics is indicated which is somehow depended on the precursor formulation. Generally, the tensile strength increases with solid content volume up to about $50 \mathrm{vol} \%$ indicating the optimum solid content loading.

In summary, SL has widely shown promises for the fabrication of ceramics with appreciable resolution and large size models. The approach is suitable for the transformation of both conventional and advanced ceramic precursors into ceramic structures with promising properties.

\section{2 Digital light processing (DLP)}

Although DLP has some similarities with SL, the major difference is that photopolymerization process of the DLP is mainly relied on image projectors (DMD) in which light with wavelength of $405 \mathrm{~nm}$ can be produced [6]. The projector is a mask-like device responsible for the projection of the image through the photosensitive liquid resin. In fact, the need for mask as light projector makes DLP more expensive when compared to SL $[132,133]$. DLP can be used to produce high resolution image with minimum size less than $50 \mu \mathrm{m}$ [6]. The technique favors small size structures like jewelry casting and dentistry. The small

Table 1 Summary of the ceramics prepared based on SL technique

\begin{tabular}{|c|c|c|c|c|c|}
\hline Precursor composition & $\eta$ & $\lambda$ & FC & TS & Ref. \\
\hline $\mathrm{ZrO}_{2}(50 \mathrm{vol} \%)+$ acrylates & - & $351-364$ & $\mathrm{ZrO}_{2}$ & - & [53] \\
\hline $\mathrm{SiO}_{2}(50$ vol $\%)+$ acrylic + silicone acrylate & $3 @ 4 \mathrm{~s}^{-1}$ & 325 & $\mathrm{SiO}_{2}$ & $52.5 \mathrm{MPa}$ & [125] \\
\hline $\mathrm{SiO}_{2}(40$ vol$\%)+$ HDDA + PEAAM & 1.71 & 353 & $\mathrm{SiO}_{2}$ & - & [126] \\
\hline $\mathrm{SiO}_{2}(60 \mathrm{vol} \%)+\mathrm{HDDA}+\mathrm{EPTA}$ & $0.58 @ 10 \mathrm{~s}^{-1}$ & 355 & $\mathrm{SiO}_{2}$ & - & [127] \\
\hline $\mathrm{SiO}_{2}(50$ vol $\%)+$ acrylates & $1.10 @ 100 \mathrm{~s}^{-1}$ & $351-364$ & $\mathrm{SiO}_{2}$ & $1.2 \mathrm{~Pa}$ & [52] \\
\hline $\mathrm{SiO}_{2}(50$ vol $\%) \mathrm{AM}+\mathrm{MBAM}+$ glycerol +water & - & - & $\mathrm{SiO}_{2}$ & - & [122] \\
\hline ZTO $(40$ vol $\%)+$ diacrylates & 0.5 & $260-550$ & $\mathrm{ZrTiO}_{3}$ & - & [128] \\
\hline ZTO $(89 w \mathrm{wt} \%)+\mathrm{HDDA}+\mathrm{PEG}+\mathrm{U} 600+$ alcohol & - & - & $\mathrm{ZrTiO}_{3}$ & - & [129] \\
\hline ZTO (45 vol\%) + HDDA + (epoxy-acrylate) & $4.8 @ 50 \mathrm{~s}^{-1}$ & $351-365$ & $\mathrm{ZrTiO}_{3}$ & - & {$[130]$} \\
\hline $\mathrm{Al}_{2} \mathrm{O}_{3}(45 \mathrm{vol} \%)+\mathrm{HDDA}+2$-HEA + TMPTA & $1.62 @ 30 \mathrm{~s}^{-1}$ & 405 & $\mathrm{Al}_{2} \mathrm{O}_{3}$ & - & {$[53]$} \\
\hline $\mathrm{Al}_{2} \mathrm{O}_{3}(50$ vol $\%)+\mathrm{HDDA}+\mathrm{PPTTA}$ & $3 @ 100 \mathrm{~s}^{-1}$ & 355 & $\mathrm{Al}_{2} \mathrm{O}_{3}$ & - & [131] \\
\hline AHPCS + acrylates & - & 405 & $\mathrm{SiOC}$ & - & [104] \\
\hline AHPCS + acrylates & - & 405 & $\mathrm{SiC}$ & - & {$[104]$} \\
\hline Silicone powder $(40 \mathrm{wt} \%)+\mathrm{MSQ}+\mathrm{TPMM}+\mathrm{TMSPM}+\mathrm{BMMB}+\mathrm{DDPE}$ & - & 250 & $\mathrm{SiOC}$ & - & [108] \\
\hline
\end{tabular}

$\bar{\eta}=$ viscosity $(\mathrm{Pa} \cdot \mathrm{s}), \lambda=$ laser wavelength $(\mathrm{nm}), \mathrm{FC}=$ final ceramic, $\mathrm{TS}=$ tensile strength; HDDA $=1,6$-hexanediol diacrylate, PPTTA $=$ ethoxylated pentaerythritol tetraacrylate, PPG400 = polypropylene glycol 400, ACMO = acryloyl morpholine, PEGDA = poly (ethylene glycol) diacrylate, IBA = isobutyl acrylate, PNPGDA = propoxylated neopentyl glycol diacrylate, $\mathrm{AM}=$ methyl acrylate, MBAM = N,N'-methylenebisacrylamide, FC = sintered ceramic, PEAAM = polyester acrylate, $\mathrm{HA}=$ hydroxyapatite, $\mathrm{ZTO}=$ zirconate titanate oxides, $\mathrm{TMPTA}=$ trimethylolpropane triacrylate, 2 -HEA = 2-hydroxyethyl acrylate, AHPCS = allylhydridopolycarbosilane, MSQ = methyl-silsesquioxane resin, TPMM = tripropylene glycol monomethyl ether, $\mathrm{TMSPM}=3$-(trimethoxysilyl)propyl methacrylate, BMMB = 2-benzyl-2-dimethylamino-1-(4-morpholinophenyl)-butanone-1, DDPE = 2,2-dimethoxy-1,2-diphenylethan-1-one. 
structures are normally produced with high precision and resolution in accordance to the CAD models [134]. DLP is mostly used for photopolymerization of radical-free photosensitive resins since it uses light source with longer wavelength [6].

Schmidt et al. [135] recently fabricated bioactive glass-ceramic scaffolds with complex structures using DLP. Polymer precursors for the scaffold were prepared by adding glass particles into photoactive polymer resins (i.e., tripropylene glycol diacrylate). The glass material has composition of $53.98 \mathrm{wt} \% \mathrm{SiO}_{2}, 34.58 \mathrm{wt} \%$ $\mathrm{CaO}$, and $11.7 \mathrm{wt} \% \mathrm{MgO}$. The ceramic-polymer matrix was thereafter printed and polymerized using DLP with light having wavelength in the range of 400-500 nm. In that research, the use of photo-absorber was avoided since the photopolymerization process is performed using light with longer wavelength. The printed structure was thus sintered at $1100{ }^{\circ} \mathrm{C}$ to remove the polymer resin, and hence final scaffold with complex structure was obtained (Figs. 14(a) and 14(b)). It was claimed that the final structure exhibited porosity and compressive strength of about $83 \%$ and $3 \mathrm{MPa}$ respectively. It shows the suitability of the DLP approach for ceramic structure engineering towards bio-technology application, such as tissue engineering.

In another report recently given by Liu et al. [32], it was revealed that structures as well as porosity of the ceramic fabricated via DLP can be substantially controlled by balancing technique-ceramic precursor properties. The research demonstrated the photopolymerization of a resin-based ceramic slurry consisting of $\mathrm{Li}_{4} \mathrm{SiO}_{4}$ and trimethyl-propane-triacrylate. In their work, 1,6-hexanediol diacrylate, 2,4,6-trimethylbenzoyl-diphenyl oxide phosphine, and fluorocarbon polymer solution were used as reactive diluent, photoinitiator, and dispersant, respectively. The steps for the slurry preparation are shown in Fig. 15(a). With the use of DLP technique, ceramic units suitable for tritium breeding were printed, and it has tritium breeder units (Figs. 15(b) and 15(c)) demonstrating its suitability for potential fusion application.

In that research, it is discovered that light exposure time can be used to solve the problem of structure deformation which often arises during sample detachment from the building platform of the DLP [32]. Specifically, two sets of light exposure time were used in which the initial $15 \mathrm{~s}$ exposure time was used to form the base for the structure while only $2 \mathrm{~s}$ light exposure time was used for the printing of the main structure. The approach aids the development of defectfree structures even after sintering treatment (Fig. 15(c)). More recently, Zhang et al. [34] also compared the elementary building units prepared for resin, and ceramics through SL and DLP techniques, which help the understanding of ceramic printing process and the dimension retention performance (Fig. 16).

$\mathrm{He}$ and Song [136] prepared photocurable $\mathrm{Al}_{2} \mathrm{O}_{3}$ slurry, and the slurry consists of aluminum oxide powder with varying loading of $2-70 \mathrm{wt} \%$ in a photocurable acrylate resin containing phosphate ester as dispersant for printing ceramic structures. As shown in Figs. 11(b) and 11(c), the viscosity and shear stress increase with $\mathrm{Al}_{2} \mathrm{O}_{3}$ loading. It in turn reduces curing depth during UV-irradiation in an SL technique. However, one may say that optimum curing depth normally achieved at $50 \mathrm{vol} \%$ of the solid content loading according to the above discussions and data reported by $\mathrm{He}$ and Song (Figs. 11(d) and 11(e)) [136]. It suggests that optimum photopolymerization of the $\mathrm{Al}_{2} \mathrm{O}_{3}$-polymer matrix can be obtained at $50 \mathrm{vol} \%$ or $\mathrm{wt} \%$ of the solid loading.

With the use of the suspension-enclosing projectionstereolithography (SEPS) as shown in Fig. 11(a), and the conventional ceramic precursor (alumina paste), $\mathrm{He}$ and Song's research shows that different geometric structures (Figs. 12(a)-12(h)) can be designed without directly attaching to the SL building platform [136]. The detachment of the printed samples was relatively simple and safe without deformation. Based on its simplicity, one may suggest that SEPS have possibility of solving the problem of structure deformation which normally occurs during detachment of printed polymers from the SL building platform.

Fu et al. [137] have recently demonstrated that porous ZrOC structure can be successfully printed using homemade precursor. The preceramic precursor is prepared by mixing zirconium n-propoxide, methylacrylic acid, and trimethylolpropane triacrylate together with diphenyl (2,4,6-trimethylbenzoyl) phosphine oxide as photoinitiator (Fig. 13(a)). The printing process and pyrolysis were performed as shown in Fig. 13(a). Although the structure exhibited linear shrinkage and mass loss of $79 \%$ and $42 \%$ respectively, high porosity of about $55.49 \%$ was obtained after pyrolyzing the green sample at temperature range of $600-1200{ }^{\circ} \mathrm{C}$ (Fig. 13(b)). It favors the realization of ultralight and ultrastrong structures (Figs. 13(c) and 13(d)). Such performance is partly attributed to the use of precursor with low viscosity and high photosensitivity [137]. 


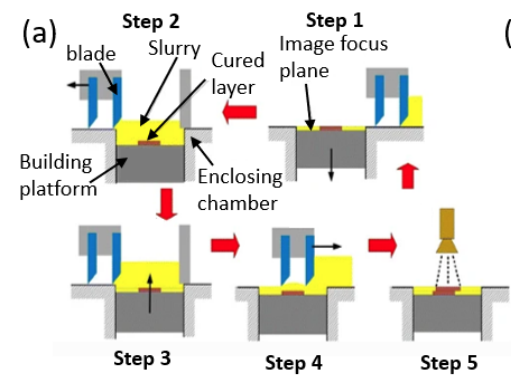

(d)

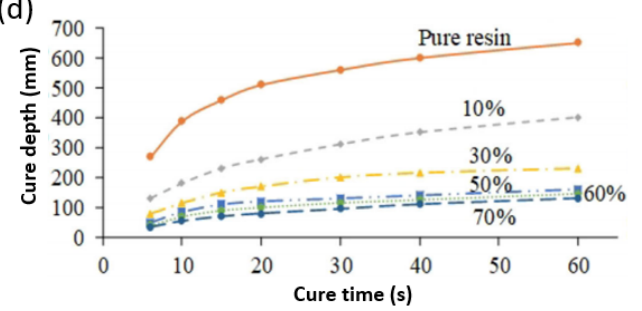

(b)

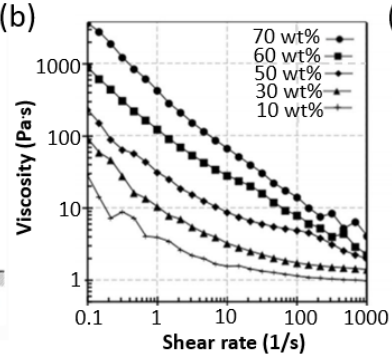

(c)

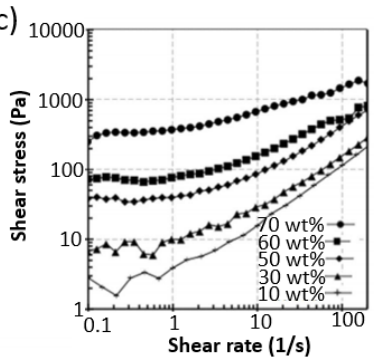

(e)

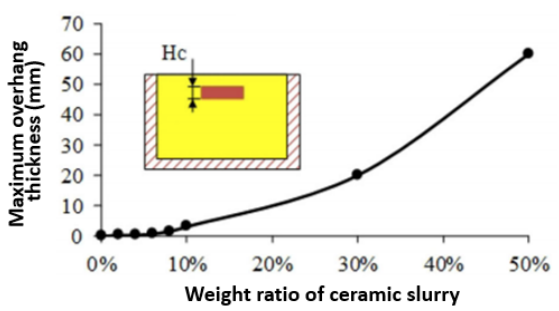

Fig. 11 (a) Schematic illustration of the printing steps of the SEPS technique. Measured data for $\mathrm{Al}_{2} \mathrm{O}_{3}$ slurry: (b) viscosity versus shear rate, (c) shear stress versus shear rate, (d) cure depth versus cure time, and (e) maximum overhang thickness versus weight ratio of the slurry. Reproduced with permission from Ref. [136], (C) The Minerals, Metals \& Materials Society 2017.
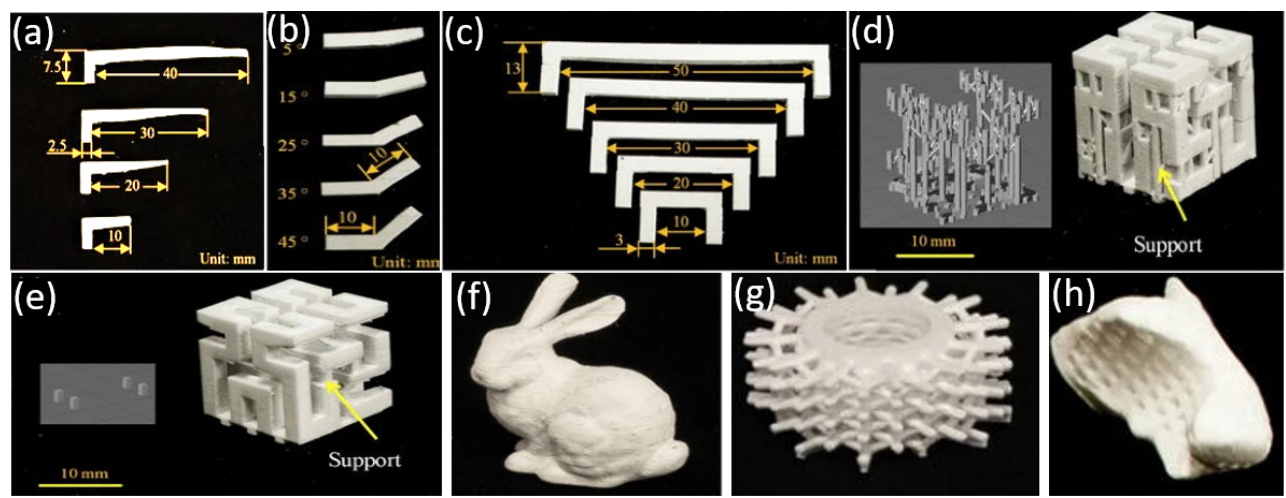

Fig. 12 Fabrication results via the SEPS process: (a) bridge-like structures, (b) cantilevered beams, (c) overhanging beams with inclination angles, (d) Hilbert cube fabricated via a traditional SL process, (e) Hilbert cube fabricated by the SEPS process, (f) Stanford bunny model, (g) heat exchanger tube, and (h) porous bone scaffold. Reproduced with permission from Ref. [136], (c) The Minerals, Metals \& Materials Society 2017.
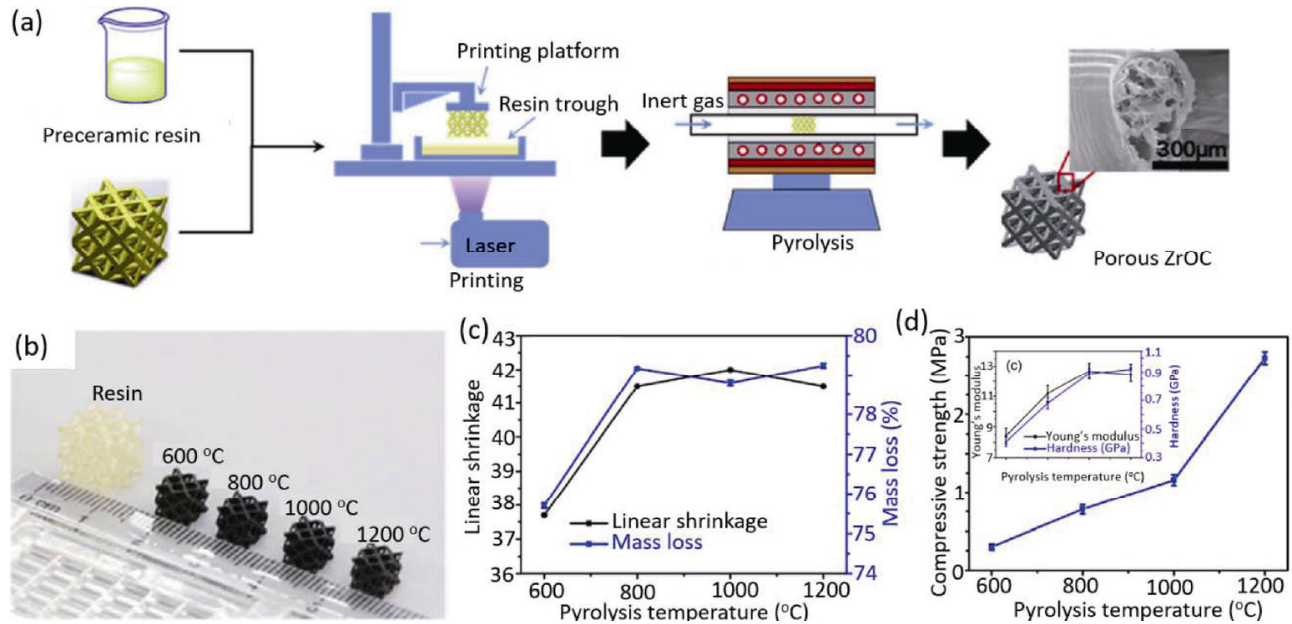

Fig. 13 (a) Schematic of the preparation route of octet truss porous structure ZrOC ceramics. (b) Photo of samples after printing and pyrolysis. (c) Linear shrinkage and mass loss. (d) Compression strength (inset corresponds to hardness and Young's modulus). Reproduced with permission from Ref. [137]. C Elsevier B.V. 2019. 
Furthermore, it may be noted that several other advanced ceramic precursors have been recently used for the fabrication of both PDCs and traditional ceramics via DLP (Table 2). However, the properties and performance of the final ceramics strongly rely on the precursor formulation. For instance, the use of solid content with small particles favors properties of the final ceramic parts as demonstrated in Table 2. This is because small particles have possibility of minimizing light scattering which may in turn increase the curing depth and width.
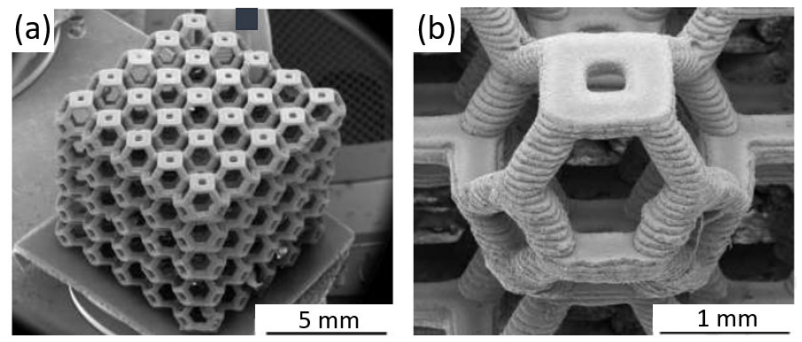

Fig. 14 SEM images of sample with (a) a Kelvin cell architecture, (b) structure at a higher magnification. Reproduced with permission from Ref. [135], (C) Elsevier Ltd. 2018.
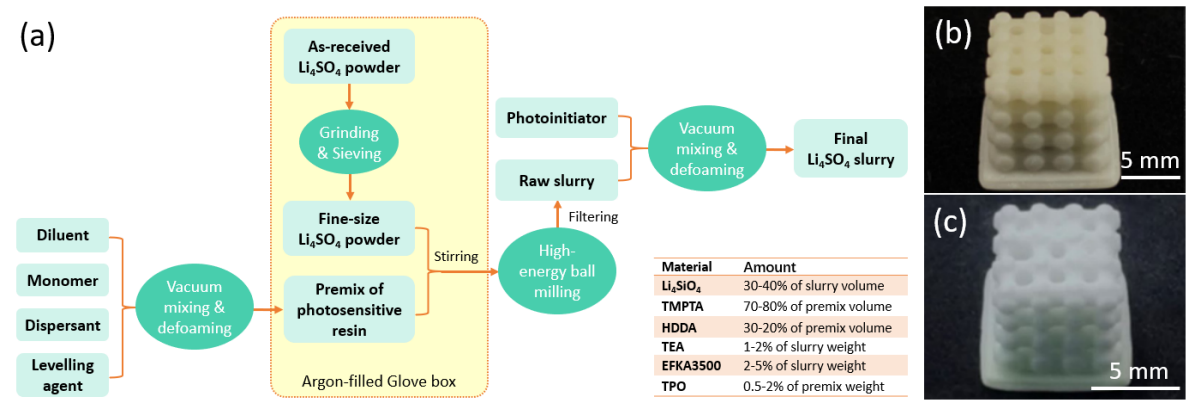

Fig. 15 (a) Illustration of preparation step for the photosensitive $\mathrm{Li}_{4} \mathrm{SiO}_{4}$ slurry. Photographs of the cellular structures of the $\mathrm{Li}_{4} \mathrm{SiO}_{4}$ ceramic: (b) as-printed, (c) as-sintered. Reproduced with permission from Ref. [32], (C) Elsevier B.V. 2020.

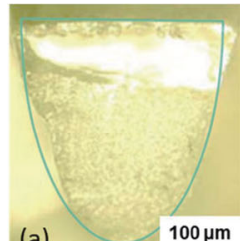

(a)
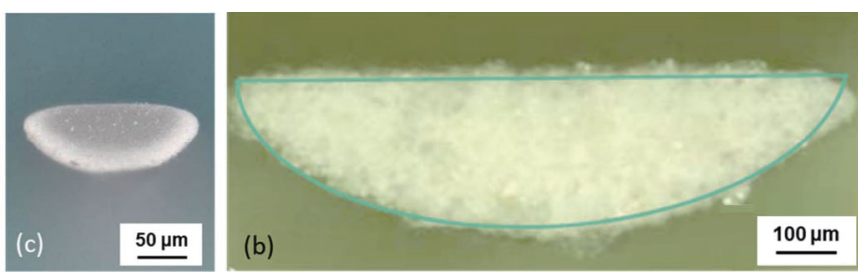

Fig. 16 Comparison of cross-sectional microstructures of photopolymerized units: (a) resin by SL, (b) silica by SL, (c) cordierite by DLP. Reproduced with permission from Ref. [34], C Elsevier Ltd and Techna Group S.r.1. 2020.

Table 2 Summary of the ceramics prepared based on DLP technique

\begin{tabular}{|c|c|c|c|c|c|}
\hline Precursor composition & $\eta$ & $\lambda$ & $\mathrm{FC}$ & TS & Ref. \\
\hline $\mathrm{ZrO}_{2}(42$ vol$\%)+\mathrm{ACMO}+$ PEGDA & $1.68 @ 18.6 \mathrm{~s}^{-1}$ & 405 & $\mathrm{ZrO}_{2}$ & $1.68 \mathrm{~Pa}$ & [138] \\
\hline $\mathrm{ZrO}_{2}(55 \mathrm{vol} \%)+\mathrm{HDDA}+\mathrm{TMPTA}$ & $1.65 @ 200 \mathrm{~s}^{-1}$ & - & $\mathrm{ZrO}_{2}$ & - & [139] \\
\hline $\mathrm{ZrO}_{2}(40 \mathrm{vol} \%)+\mathrm{AM}+\mathrm{MBAM}+$ glycerol + water & 0.127 & - & $\mathrm{ZrO}_{2}$ & 2.00 Pa & [140] \\
\hline ZTO $(18$ vol $\%)+$ PZT + HDDA + methacrylate + acrylate & - & - & $\mathrm{ZrTiO}_{3}$ & - & {$[68]$} \\
\hline $\mathrm{Al}_{2} \mathrm{O}_{3}(56 \mathrm{vol} \%)+\mathrm{HDDA}+\mathrm{PPTTA}$ & - & 405 & $\mathrm{Al}_{2} \mathrm{O}_{3}$ & - & [141] \\
\hline $\mathrm{Al}_{2} \mathrm{O}_{3}(50 \mathrm{vol} \%)+\mathrm{HDDA}+\mathrm{PPTTA}+\mathrm{PPG} 400 \mathrm{~b}$ & $3.98 @ 100 \mathrm{~s}^{-1}$ & 405 & $\mathrm{Al}_{2} \mathrm{O}_{3}$ & $13.26 \mathrm{~Pa}$ & [142] \\
\hline $\mathrm{Al}_{2} \mathrm{O}_{3}(40 \mathrm{vol} \%)+\mathrm{HDDA}+\mathrm{TMPTA}$ & $3 @ 45 \mathrm{~s}^{-1}$ & 364 & $\mathrm{Al}_{2} \mathrm{O}_{3}$ & - & [143] \\
\hline $\mathrm{ZrO}_{2}(58 \mathrm{vol} \%)+\mathrm{HDDA}+\mathrm{IBA}+\mathrm{PNPGDA}$ & $9.02 @ 5 \mathrm{~s}^{-1}$ & $375-425$ & $\mathrm{ZrO}_{2}$ & $6.74 \mathrm{MPa}$ & [144] \\
\hline $\mathrm{Si}_{3} \mathrm{~N}_{4}+\mathrm{HDDA}+\mathrm{TMPTA}$ & - & 405 & $\mathrm{Si}_{3} \mathrm{~N}_{4}$ & - & [145] \\
\hline Methyl-silsesquioxane + TMPTA + TGME + 3-TPMA & - & 405 & $\mathrm{SiOC}$ & $0.124 \mathrm{MPa}$ & [109] \\
\hline $\mathrm{Al}_{2} \mathrm{O}_{3} \cdot 2 \mathrm{SiO}_{2}(45 \mathrm{vol} \%)+\mathrm{PEGDA}+3-\mathrm{MA}+\mathrm{TTBP}$ & - & 365 & $\mathrm{Al}_{2} \mathrm{O}_{3}-2 \mathrm{SiO}_{2}$ & $9.98 \mathrm{MPa}$ & [146] \\
\hline Cordierite powder (40-50 vol\%) + HDDA + TMPTA & $1.49 @ 100 \mathrm{~s}^{-1}$ & 405 & $\mathrm{Mg}_{2} \mathrm{Al}_{4} \mathrm{Si}_{5} \mathrm{O}_{18}$ & - & {$[10,147]$} \\
\hline Lithium orthosilicate (up to $60 \mathrm{vol} \%$ ) + HDDA + TMPTA & $10.95 @ 100 \mathrm{~s}^{-1}$ & 405 & $\mathrm{Li}_{4} \mathrm{SiO}_{4}$ & - & [32] \\
\hline $\mathrm{Al}_{2} \mathrm{O}_{3}(30$ vol $\%)+$ PEGDA & - & $295-370$ & $\mathrm{Al}_{2} \mathrm{O}_{3}$ & $0.395 \mathrm{MPa}$ & [148] \\
\hline Polysiloxane & - & 405 & $\mathrm{SiOC}$ & - & [149] \\
\hline $\mathrm{Al}_{2} \mathrm{O}_{3}(52 \%)+$ acrylates & - & 405 & $\mathrm{Al}_{2} \mathrm{O}_{3}$ & $142.2 \mathrm{MPa}$ & {$[150]$} \\
\hline TMOS + MTMS + APTMS & - & $400-760$ & Organic-ceramic hybrid & $69 \mathrm{MPa}$ & [151] \\
\hline Polyvinylsilazane $+\mathrm{SiO}_{2}(30 \mathrm{wt} \%)$ & - & $380-440$ & $\mathrm{SiCN}$ & $10 \mathrm{GPa}$ & [152] \\
\hline
\end{tabular}

$\eta=$ slurry viscosity $(\mathrm{Pa} \cdot \mathrm{s}), \lambda=$ light wavelength $(\mathrm{nm}), \mathrm{FC}=$ final ceramic, $\mathrm{TS}=$ tensile strength; TMPTA $=$ trimethylolpropane triacrylate, $\mathrm{TGME}=$ tripropylene glycol monomethyl ether, 3-TPMA $=3$-(trimethoxysilyl) propyl methacrylate, 3-MA = 3,3-dimethylacrylic acid, TTBP = 2,4,6-trimethylbenzoyldiphenyl, TMOS = tetramethylorthosilicate, MTMS = trimetoxymethylsilane, APTMS = 3-acryloxypropyltrimethoxysilane. 
In summary, DLP is an approach suitable for the fabrication of structures with high resolution and precision. It has faster printing rate when compared to SL. However, the approach is not suitable for the fabrication of material with large size. The use of mask-like devices for image projection contributes to the printing cost, and hence makes DLP slightly more expensive when compared to SL.

\section{3 Two-photon polymerization (TPP)}

TPP is a $3 \mathrm{D}$ printing technique in which photopolymerization of ceramic precursor takes place by absorbing two photons of light at wavelength of near infrared $(\sim 780 \mathrm{~nm})$ or green laser beam $(515 \mathrm{~nm})$ [6]. With the use of this technique, the photopolymerization normally occurs within a spatially localized focal spot in the photosensitive resin (Fig. 17(a)) [153]. Therefore, this technique is mostly suitable for preceramic precursor resins than conventional ceramic-polymer matrix as the latter is generally opaque to the incident light. The approach can offer ceramics with nanosized structures making it relevant for the printing of ceramics for nanotechnology application. In fact, TPP has been widely used for the printing of objects with high resolution of $<200 \mathrm{~nm}$ which seems not obtainable through other techniques that are based on single photon photopolymerization process $[154,155]$.

It is worth noting that TPP technique is mostly useful for the printing and fabrication of polymeric materials $[6,156,157]$. However, the need for nanostructured ceramics particularly in the field of nanotechnology has expanded the use of this technique to the ceramic fabrication. Recently, Brigo et al. [158] used TPP technique to investigate the influence of printing process and precursor formulation on the nanostructures of the SiOC. In that research, acrylate siloxane and bis(dimethylamino)benzophenone (BDEBP) were mixed and used as preceramic precursor for the printing of SiOC. The printing process was performed using radical photopolymerization approach with light source having wavelength of $\sim 365 \mathrm{~nm}$ [158].

Brigo et al.'s research revealed that SiOC structures with high resolution and height in the range of $100 \mu \mathrm{m}^{-1} \mathrm{~mm}$ (Fig. 17) can be fabricated depending on the printing process. It is discovered that a layer-bylayer structure growth is possible through a bottom-up printing system with laser beam focusing on lower glass-resin interface. The structures were then grown along the $z$-coordinated direction. The printing process was performed by placing precursor droplets between two glass substrates separated by polydimethylsiloxane (PDMS) membrane as gasket (Fig. 17(b)) [158]. The laser beam was then scanned at the upper glass-resin interface which in turn gave rise to layer-by-layer growth of the structure in decreasing pattern along the $Z$-coordinate [158]. The approach gave rise to structures
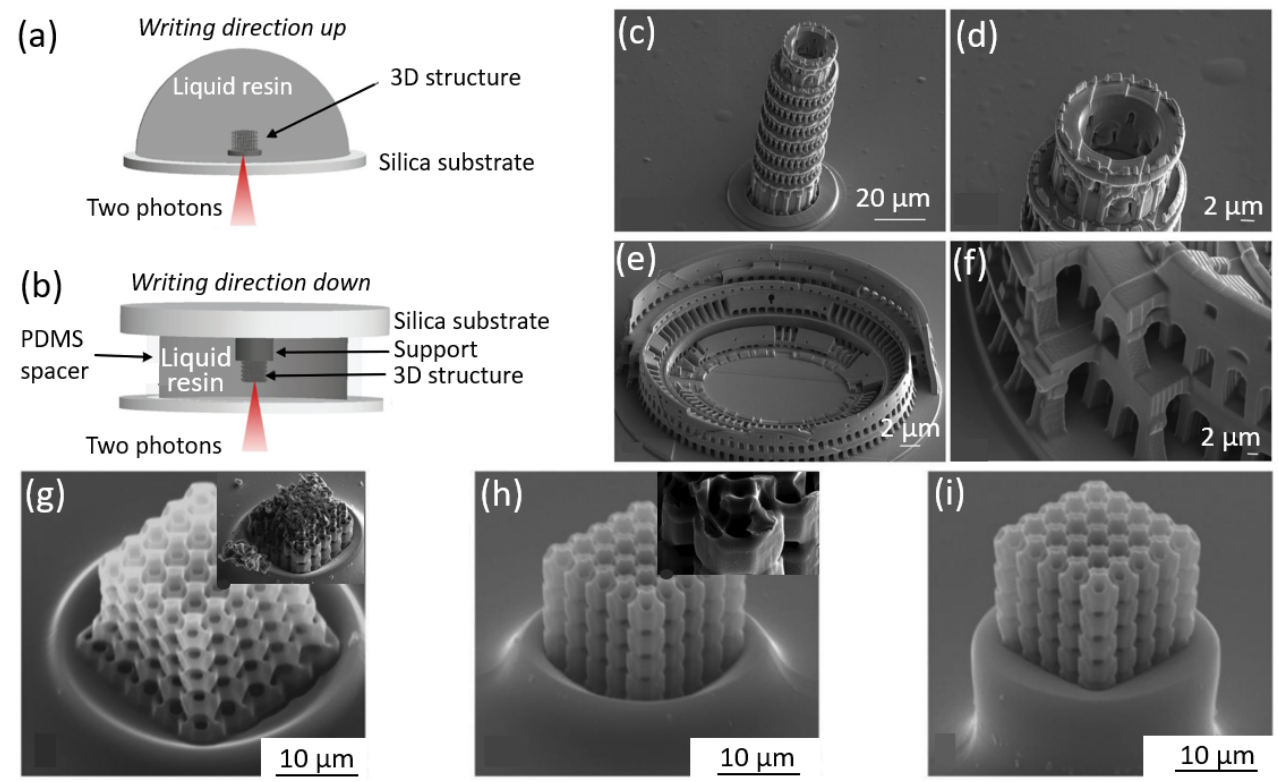

Fig. 17 Schematics of (a) the "standard" approach with writing direction: up, and (b) "inverted" configuration with writing direction: down for 3D printing of SiOC ceramics. The complex 3D structures of the SiOC produced using the preceramic resist: before pyrolysis (c, d) Pisa tower, (e, f) Colosseum, (g-i) the pyrolyzed Kelvin cell on support base. Reproduced with permission from Ref. [158]. (C) The Authors 2018. 
with complex geometries (Figs. 17(c)-17(f)). Even though the structure underwent a slight deformation depending on the height of the support pillars (inset of Fig. $17(\mathrm{~g})$ ), a crack-free surface was observable after pyrolyzing at $1000{ }^{\circ} \mathrm{C}$ (inset of Fig. 17(h)).

In addition, TPP has also been widely used as an auxiliary approach to support other techniques, and hence photopolymerized ceramics in the range of micro to nanosize were produced [6]. Oftentimes, strategies are aimed to develop porous scaffolds or hollow structures. With the use of this approach, polymer matrix containing $\mathrm{SiO}_{2}, \mathrm{TiN}, \mathrm{Al}_{2} \mathrm{O}_{3}$ were printed into $3 \mathrm{D}$ hollow structures [159-161]. For instance, Meza and Greer [160] demonstrated the use of TPP coupled with direct laser writing, atomic layer deposition (ALD), and $\mathrm{O}_{2}$ plasma etching (Fig. 18) for the fabrication of TiN ceramic with nanolattices structures (Figs. 18(b)18(e)). The final material exhibits high von Mises stress and tensile strength of 2.50 and $98 \mathrm{GPa}$, respectively [160]. With a similar approach, $\mathrm{SiO}_{2}$ microlattice and $\mathrm{Al}_{2} \mathrm{O}_{3}$ nanolattice with hollow-structures have been reported too [159]. All of these show the relevance of the TPP for the photopolymerization of ceramic precursors into ceramics with micro-nanosizes.

In summary, one may note that among the photopolymerization techniques relevant for the fabrication of ceramics, TPP is the most suitable for submicron scale PDC fabrication. The approach is suitable for incurporating porous surface into ceramic structures too. This thus makes the approach relevant for the production of $3 \mathrm{D}$ printed ceramics for nanotechnology applications.

\section{Other potential photopolymerization-based AM techniques for ceramic fabrication}

There are still a number of recently developed photopolymerization-based AM techniques which have been used for the 3D printing of polymeric materials but not yet employed for ceramic 3D printing. Three kinds of representative techniques including liquid crystal display (LCD) printing, continuous liquid interface production (CLIP), and multi-jet printing (MJP), are briefly presented and discussed here.

\section{1 Liquid crystal display (LCD) printing}

LCD is one of the latest and much affordable photopolymerization-based AM techniques with a bottom-up printing system [162]. The approach is similar to the DLP and SL but with different imaging system $[162,163]$. Specifically, LCD uses liquid crystal display for the imaging of the polymer resins [9]. Its fundamental principle is based on the use of electric field to cause spontaneous changes in the molecule rearrangement of liquid resins [9]. This normally results in monomer polymerization, and hence prevents further penetration of light [164].
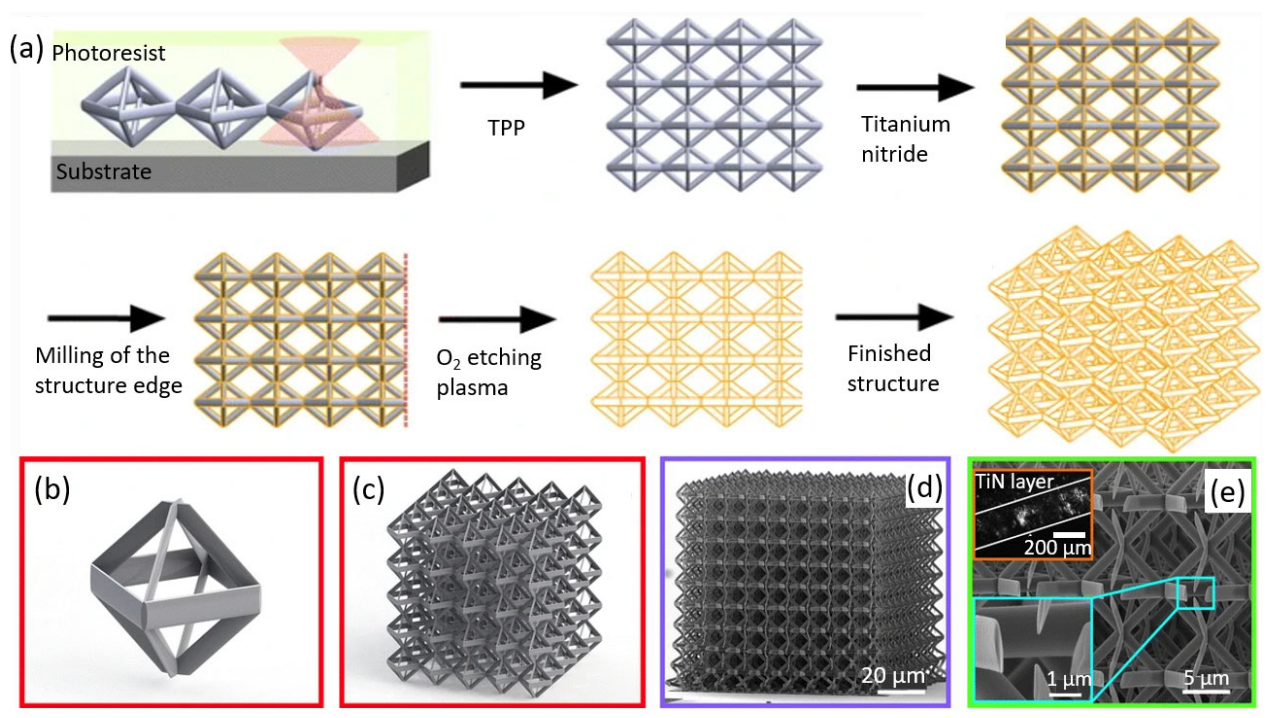

Fig. 18 (a) Schematic representation of the writing process of the lattice unit cells using two-photon lithography direct laser writing. (b) CAD model of a unit cell, (c) CAD model of the full lattice, (d) SEM image of the as-prepared full octahedron structure, (e) SEM image of the FIB milled edge of a nanolattice. Top left inset shows a dark-field TEM image of the TiN microstructure, which reveals nano-sized grains. Bottom left inset is a zoomed image of the hollow tubes. Reproduced with permission from Ref. [160], (C) Springer Science Business Media New York 2013. 
LCD offers appreciable image resolution, but the precision is somehow lower than that of traditional DLP. This is because the molecules of liquid crystal normally undergo incomplete polymerization and/or rearrangement and hence causes light leakage [9]. Even though much attention has not been given to the use of LCD for the polymerization of ceramic materials, the approach is suitable for the photopolymerization of preceramic materials. This is because free-radical and cationic photopolymerization process is possible through this technique [9].

In summary, LCD is a cheap 3D printing technique, and it can be used for the fabrication of structure with good resolution. However, the technique has not received the needed attention for the printing of ceramics. It is a research that needs attention since LCD has potential to reduce the cost associated with material printing. Furthermore, the short-life span of the LCD screen is another issue hindering its use for ceramic fabrication. Therefore, one may suggest that increasing the light emitting capacity of the LCD screen may in turn give rise to its long-life span. This may enhance the possibility of emitting strong light intensity too, and hence make the technique relevant for wider range of materials.

\section{2 Continuous liquid interface production (CLIP)}

CLIP is a 3D printing developed by the Carbon 3D Corp. $[14,165]$. The technique is similar to DLP. However, it consists of a special module in which there is incorporation of an oxygen permeation membrane (Fig. 19). The specialization is normally used to inhibit free-radical polymerization. The membrane at the bottom can allow the in-flow of the light beam and oxygen. The oxygen is often expected to quench the photo-excited radical or formed peroxide by interacting with the free radical [166]. This results in the formation and retain of liquid resin at the bottom while the polymerization takes place on top [9]. The technique has been used for the printing of polymeric resins in which structures with appreciable resolution are obtained $[14,165]$.

The printing rate of CLIP is about 25 times and above greater than that of DLP. CLIP offers structures with higher precision. This is because the continuous printing prevents the physical layer appearance on the side surface of the printed parts. Compared with DLP printing, no staircase effect is generated so that the properties of the printed parts can be more isotropic.

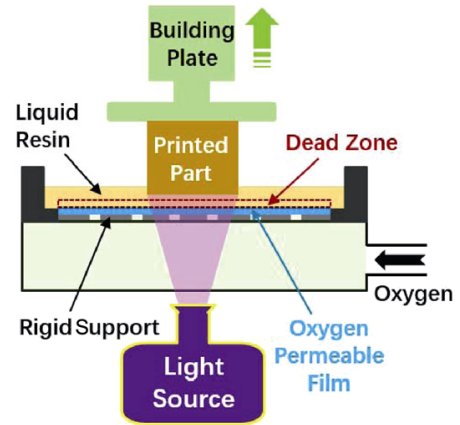

Fig. 19 Schematic illustration of CLIP 3D printing technique.

All of these show the suitability of the approach for polymerization of ceramic materials, particularly for printing PDCs using low-viscosity preceramic precursors [167]. However, to the best of our knowledge, the technique has not yet been extended to the printing of ceramic, because the involvement of ceramic content extremely increase the viscosity of the slurries so that the flowing of the liquid within the dead zone would be highly challenging.

\section{3 Multi-jet printing (MJP)}

Multi-jet printing is an AM technique that consists of multiple nozzles [9]. The technique is often used to print structures with multiple colors (i.e., for decoration or demonstration purpose) since inks with different colors can be injected at a time. MJP is designed in such a way that its nozzles can spray photosensitive liquid resins layer by layer. With the use of the technique, individual layers can be printed and cured before adding the subsequent ones. In particular, the nozzles spray a layer on the building platform, and the spread layer will then be smoothened and flattened by the roller and followed by photocuring using a UV lamp [9]. The next layer will then be sprayed by the nozzles and treated in a way similar to the previous layer until the part fabrication is complete.

MJP technique can be used for photopolymerization of wide range of photosensitive materials of relevance to radical, cationic, and hybrid photopolymerization [9]. This is because it has a light source with a wide range of wavelength $(355-405 \mathrm{~nm})$. Similar to the inkjet printing, MJP needs inks with low viscosity in order to avoid blockage of the nozzles. This is because its nozzles are in pico-size nature [9]. All of these make MJP a relevant 3D printing approach suitable for the printing and decoration of ceramics. Currently, only little is known about this approach for the photo- 
polymerization of ceramic materials. However, it is worth noting that the technique has complex components, and the material preparation is complex too since low viscosity is a prerequisite. It thus makes the whole process complicated and expensive.

\section{Ceramic functionalities obtainable via photopolymerization-based AM}

The functionalities of ceramics derived through photopolymerization-based AM are normally dependent on the precursor composition regardless of the techniques. Nonetheless, it is worth noting that techniques have plausible contribution too since they are relevant for tailoring structural properties. As shown in Table 3, DLP and SL are mainly useful for dense and microporous structures while TPP is relevant for tailoring nanostructures. In addition, it is worth noting that polymerization-based AM techniques have shown possibility for printing ceramics for biomedical applications [168]. This is due to their ability to fabricate complex structures coupled with the relevance for internal structure engineering [169]. However, it is worth noting that due to the particle densification and coarsening of ceramics after thermal post-treatment of printed parts, the porosity of the final structures is normally reduced greatly [169], which to some extent hinders the suitability of the printed ceramics for bioceramic application as generally high porosity is more desirable [169]. Therefore, in this section, mechanical, catalytic, electrical, and optical/photonic applications of ceramics prepared through photopolymerization-based AM are the major functionalities that will be discussed.

The efficiency of the functionalities depends however on the precursor compositions [170]. For example, fillers (e.g., carbon, silica etc.) have so far been used to

Table 3 Properties and applications of ceramics fabricated by photopolymerization-based AM

\begin{tabular}{lll}
\hline $\begin{array}{l}\text { Tech- } \\
\text { nique }\end{array}$ & Ceramic structural engineering & \multicolumn{1}{c}{ Functionalities } \\
\hline & & Microelectronics [174] \\
& Highly dense structure [13,171] & Optical parts [175,176] \\
SL & Microporous [172,173] & Bioceramic scaffold [172, \\
& & Dental components [170] \\
\hline \multirow{2}{*}{ DLP } & Highly dense and hard structure [147] & Heat exchangers [177] \\
& Microporous [158] & Catalyst [32] \\
\hline \multirow{2}{*}{ TPP } & Nano/microporous [178] & Optical part [180] \\
& Nanolattices [179] & Microelectronics [181] \\
\hline
\end{tabular}

enhance the structural and functional performance of photopolymerization-based AM of ceramics with reduced shrinkage. In this section, the recent advances made by compromising precursor composition for tailoring functionalities of ceramics prepared by photopolymerization-based AM techniques are discussed.

\section{1 Mechanical and catalytic/electrical performance}

Mechanical performance of ceramics prepared by photopolymerization-based AM normally exhibit substantial improvement by introducing fillers into their precursors (i.e., liquid resin-ceramic powder mixture). Fillers are useful for the textural reinforcement in order to reduce shrinkage during post-thermal treatment (i.e., sintering). This is because, during sintering, organic monomer removal will create voids which may in turn result in structural weakness. However, properties of filler-monomer-ceramic powder mixtures are needed to be well compromised in order to form printable slurry. Uniform distribution of fillers with the liquid resin-ceramic powder mixture is essential to ensure efficient printing process. This can be done by employing fillers with particle sizes that match well with that liquid resin-ceramic powder mixture.

An example of the above is the research conducted by Pham et al. [182], where silica was used as filler for improving mechanical performance of SiCN ceramics printed via TPP technique. In their study, nano- to microstructures of SiCN ceramics was fabricated using polyvinylsilazane functionalized with 2-isocyanatoethyl methacrylate resin as precursor. The printed materials were pyrolyzed at $600{ }^{\circ} \mathrm{C}$ in $\mathrm{N}_{2}$ atmosphere. The use of varying amount $(20 \%-40 \%)$ of silica as filler resulted in shrinkage reduction with the increase in the silica content (Figs. 20(a)-20(f)). It is therefore suggested that the silica reduces the deformation and pore volumes during and after the pyrolysis. Moreover, it was discovered that silica with particle size of $\sim 10$ $\mathrm{nm}$ was compatible with, and well distributed in the ceramic precursor for efficient printing process [182]. It in turn improves the mechanical performance of the final $\mathrm{SiCN}$ ceramics.

It is worth noting that strategies similar to the above are being used to improve the electrical conductivity performance of final ceramic parts derive through photopolymerization-based AM. In that regard, the use of carbon and graphene as fillers to functionalize and modify ceramic precursors is common. The approach 
(a)
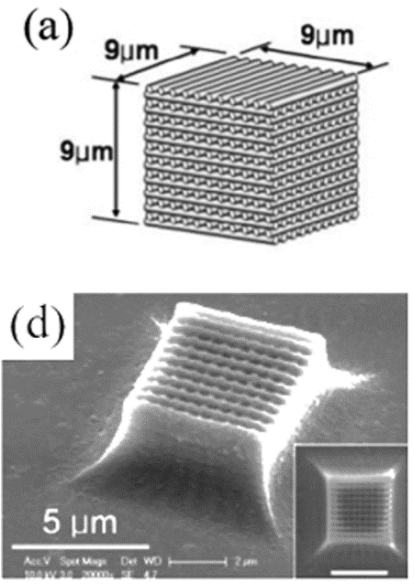

(b)
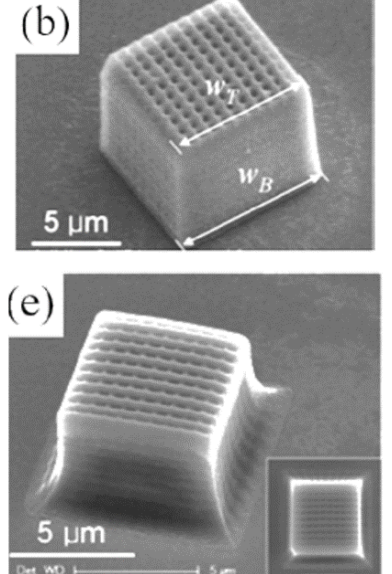
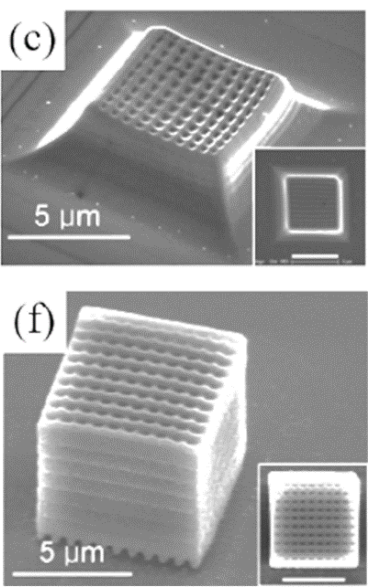

Fig. 20 SiCN ceramics fabricated via TPP technique: (a) model design for the structure; $(b, c)$ SiCN ceramic without filler. SiCN ceramics obtained from mixed resin containing various amounts of silica filler for reduced shrinkage: (d) $20 \mathrm{wt} \%$, (e) $30 \mathrm{wt} \%$, and (f) $40 \mathrm{wt} \%$. Reproduced with permission from Ref. [182], C WILEY-VCH Verlag GmbH \& Co. KGaA, Weinheim 2006.

has also been found relevant for incorporating pores into photopolymerization-based AM derived ceramics. Nevertheless, the property and functional group of the introduced fillers are essentially necessary to be compatible with that of the liquid resin-ceramic powder or preceramic mixtures.

Mei et al. [183] recently demonstrated the use of DLP for the fabrication of photocatalytic molybdenum sulfide $\left(\mathrm{MoS}_{2}\right)$-modified $\mathrm{Al}_{2} \mathrm{O}_{3}$ ceramics. In that research, carbon was employed as a pore former and reinforcement to functionalize ceramics containing $\mathrm{MoS}_{2}$ (i.e., catalytic active material). The use of DLP for the printing of slurry consisted of $\mathrm{Al}_{2} \mathrm{O}_{3}$ and resin also aids the formation of ceramics with complex microstructures [183]. The printed ceramics were thereafter sintered and functionalized with $\mathrm{MoS}_{2}$ taking advantage of pores created by the carbon formed from pyrolyzed resin. It in turn enhances electron and hole conductivity of the final ceramics triggered by well exposed active sites in the structure. This favors the catalytic application of the prepared ceramics.

\section{2 Optical/photonic performance}

SL and DLP can also be used to print components for optical and photonic applications, particularly in macroscale since it is useful for the fabrication of complex and small size structures. In this process, ceramic powders (e.g., zirconium oxide $\left(\mathrm{ZrO}_{2}\right)$, titanium oxide $\left(\mathrm{TiO}_{2}\right)$, and silica $\left.\left(\mathrm{SiO}_{2}\right)\right)$ with refractive index of $\leqslant$ 1.7 are normally used in order to generate suitable photonic properties. The powders are essentially needed to be mixed with photocurable resin (e.g., acrylate based resins) for efficient printing process. For example, Kirihara and Niki [176] demonstrated the printing of photonic crystals from a mixture of liquid $\mathrm{Al}_{2} \mathrm{O}_{3}$-acrylate resin. The printed materials were then debinded and sintered at $600{ }^{\circ} \mathrm{C}$ for $2 \mathrm{~h}$ and $1500{ }^{\circ} \mathrm{C}$ for $2 \mathrm{~h}$, respectively. The final photonic crystals of alumina with micro-lattice structures were obtained (Figs. 21(a)-21(c)).
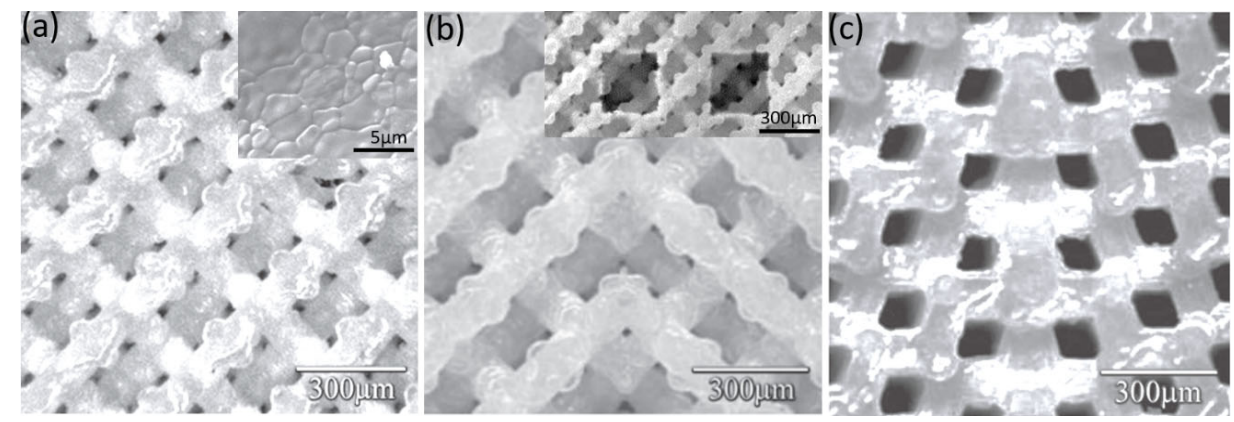

Fig. 21 (a) $\mathrm{Al}_{2} \mathrm{O}_{3}$ ceramic parts with photonic crystal appearance after debinding and sintering treatments (inset corresponds to microstructure). Twinned photonic crystals of the sintered alumina lattices corresponding to (b) (100) plane, and (c) (111) plane of diamond lattice domains (inset of (b) corresponds to the sintered alumina lattices with double-defect cavities). Reproduced with permission from Ref. [176], (C) The American Ceramic Society 2014. 
Similar to the above, Chen et al. [175] used SL for printing of photonic crystal of $\mathrm{SiO}_{2}$ ceramics. They claimed that $\mathrm{SiO}_{2}$ powders with particle size of about $100 \mathrm{~nm}$ were found suitable for the SL printing after mixing with acrylate based resins. This gave rise to photonic crystals of $\mathrm{SiO}_{2}$ ceramics with diamond like structures. All of these show suitability of SL for printing of ceramics with photonic and optical properties. However, material-printing process correlation is crucial for achieving efficient printing process.

It is worth noting that TPP technique has been found useful for printing photonic crystals in sub-micrometer scales. For example, Duan et al.'s research [184] reveals that photonic crystals of $\left(\mathrm{TiO}_{2}\right)$ ceramics can be printed into micrometer scale. Titanium (IV) acrylate complexes were used as precursor wherein $\mathrm{TiO}_{2}$ nanoceramics were generated in-situ after photopolymerization, hydrolysis, and sintering process. In short, one may summarize that photopolymerization-based AM techniques are useful for printing ceramics with desirable optical/photonic properties. Among them, SL and TPP have been widely used for printing photonic crystals in the macro- and microscale, respectively. Moreover, $\mathrm{ZrO}_{2}, \mathrm{Al}_{2} \mathrm{O}_{3}, \mathrm{TiO}_{2}$, and $\mathrm{ZrO}_{2}$ are the potential materials currently showing appreciable functionalities.

\section{Challenges, prospects, and summary}

Although, photopolymerization-based AM techniques are suitable for the fabrication of ceramics with complex geometries, several barriers are hindering commercialization of a vast number of these techniques. For instance, nearly all of the photopolymerizationbased AM techniques require materials with low viscosity for efficient printing process. This often complicates the ceramic precursor preparation, and hence adds to the cost of the printing process. It makes the whole process cumbersome. Furthermore, liquid or preceramicbased resins with low viscosity are prone to high degree of molecular crosslinking. Generally, this further weakens the structural property of the final ceramics.

In addition, most photopolymerization-based AM techniques require multiple steps of post treatments (e.g., pyrolysis and sintering) of the printed ceramics. Such thermal treatments for the removal of the organic phases may result in the formation of a large number of voids and pores. It may hence weaken the structural performance. One may therefore suggest that researches on photopolymerization-based AM technique-material correlation are needed for further strengthening, in order to fabricate ceramics that are viable for advanced applications.

Specifically, the current barriers for the use of stereolithography for ceramic printings are:

- Slow printing process delaying the delivery of the printed ceramic parts.

- Multiple steps of post-processing of the printed ceramic parts adding to the cost of the final ceramic parts.

- The use of toxic monomer resins making ceramic precursors preparation and post-treatment unfriendly to the human and environment.

- Lack of suitable light intensity for engineering the internal structure of the printed ceramic parts restricting the applications of SL printed ceramic parts.

DLP technique's main challenge is:

- Limited projection area restricting the techniques to ceramic parts with small and medium sizes.

For TPP, the identified challenges are as following:

- The laser beam is only met for the curing of transparent polymeric materials limiting the number of ceramic materials that can be processed.

- The technique is restricted to the fabrication of ceramic parts with small sizes at micro-nanoscales.

- The printing rate is very slow due to ultra-fine resolution to be realized.

Nevertheless, photopolymerization-based AM of ceramics offers substantial prospective value. Examples of prospective opportunities that may be derived through commercialization of photopolymerizationbased AM for the ceramics fabrication based on ceramic-monomer matrix or preceramic precursors are (a) production of load-bearing structural components with high resolution and precision, complex geometries, and zero defect, (b) fabrication of functional parts with micro-nanosize porous features for the applications in bio-engineering and energy storage/conversion. When the material-printing process correlation is well engineered, photopolymerization-based AM-derived ceramics may have the tendency to perform better than that are prepared through other kinds of 3D printing techniques.

For example, the use of hydrogels for the printing of bioceramic parts has shown promises in which bio- 
ceramics can be directly printed on the cells or bioactive molecules via photopolymerization-based AM techniques (e.g., DLP) [185]. It thus makes the production of highly flexible and bioactive ceramic parts possible [186]. Based on material-printing process compromising, particularly by using hydrogel to aid ceramic curing, a direct bioprinting of ceramics for bone regeneration that relies on natural body environment has been proposed too [186]. However, once again, slow printing process and the reliance on the toxic organic substances for the printing of bio-ceramics are still part of issues needed to be tackled. Therefore, development of non-toxic and printable bio-ceramic slurries with high curable ability at room temperature is thus suggested as a research in right direction to aid advanced tissue engineering via photopolymerization-based AM techniques. This is because in-situ bioprinting of ceramic scaffold for bone regeneration will be made possible without fear of further damage to the affected tissues.

In summary, photopolymerization-based AM offers a solution to the common problems (brittleness and crack) involved with machining of ceramics. The solution may bring about fabrication of ceramic components with high resolution and complex geometric structures. It may in turn increase the prospects of 3D printed ceramics across the mechanical, electronic, optical, biotechnical, and nanotechnical industries. The use of relevant material-printing process strategy is crucial for printing of ceramics with advanced properties. It is believed that the discussion given herein will offer deeper insights into the use of different photopolymerization-based AM techniques for the fabrication of advanced ceramics with superior properties and performance. The barriers and challenges to the use of photopolymerization-based AM techniques are outlined, and they are expected to benefit the researchers, scientists, and engineers whose interest matters most on the use of photopolymerization-based AM for the fabrication of ceramics for advanced applications.

\section{Acknowledgements}

This work is supported by Key Project Fund for Science and Technology Development of Guangdong Province (2020B090924003), National Natural Science Foundation of China (51975384), Guangdong Basic and Applied Basic Research Foundation (2020A1515011547), and Shenzhen Fundamental Research Project (JCYJ20190808144009478, WDZC2021023519389248).

\section{References}

[1] Padture NP. Advanced structural ceramics in aerospace propulsion. Nat Mater 2016, 15: 804-809.

[2] Janssen R, Scheppokat S, Claussen N. Tailor-made ceramicbased components-Advantages by reactive processing and advanced shaping techniques. J Eur Ceram Soc 2008, 28: $1369-1379$.

[3] Rakshit R, Das AK. A review on cutting of industrial ceramic materials. Precis Eng 2019, 59: 90-109.

[4] Montanaro L, Coppola B, Palmero P, et al. A review on aqueous gelcasting: A versatile and low-toxic technique to shape ceramics. Ceram Int 2019, 45: 9653-9673.

[5] Nishihora RK, Rachadel PL, Quadri MGN, et al. Manufacturing porous ceramic materials by tape casting-A review. J Eur Ceram Soc 2018, 38: 988-1001.

[6] Chen ZW, Li ZY, Li JJ, et al. 3D printing of ceramics: A review. J Eur Ceram Soc 2019, 39: 661-687.

[7] Liu SS, Li M, Wu JM, et al. Preparation of high-porosity $\mathrm{Al}_{2} \mathrm{O}_{3}$ ceramic foams via selective laser sintering of $\mathrm{Al}_{2} \mathrm{O}_{3}$ poly-hollow microspheres. Ceram Int 2020, 46: 4240- 4247.

[8] Wu JM, Li M, Liu SS, et al. Preparation of porous $\mathrm{Al}_{2} \mathrm{O}_{3}$ ceramics with enhanced properties by SLS using $\mathrm{Al}_{2} \mathrm{O}_{3}$ poly-hollow microspheres (PHMs) coated with $\mathrm{CaSiO}_{3}$ sintering additive. Ceram Int 2020, 46: 26888-26894.

[9] Quan HY, Zhang T, Xu H, et al. Photo-curing 3D printing technique and its challenges. Bioact Mater 2020, 5: 110-115.

[10] Chen ZW, Li JJ, Liu CB, et al. Preparation of high solid loading and low viscosity ceramic slurries for photopolymerization-based 3D printing. Ceram Int 2019, 45: 11549-11557.

[11] Hull CW. Apparatus for production of three- dimensional objects by stereolithography. Patent US. 1998.

[12] Mitteramskogler G, Gmeiner R, Felzmann R, et al. Light curing strategies for lithography-based additive manufacturing of customized ceramics. Addit Manuf 2014, 1-4: 110-118.

[13] Chen ZW, Li DC, Zhou WZ. Process parameters appraisal of fabricating ceramic parts based on stereolithography using the Taguchi method. Proc Inst Mech Eng Part B: J Eng Manuf 2012, 226: 1249-1258.

[14] Tumbleston JR, Shirvanyants D, Ermoshkin N, et al. Continuous liquid interface production of $3 \mathrm{D}$ objects. Science 2015, 347: 1349-1352.

[15] Yves-Christian H, Jan W, Wilhelm M, et al. Net shaped high performance oxide ceramic parts by selective laser melting. Phys Procedia 2010, 5: 587-594.

[16] Wilkes J, Hagedorn YC, Meiners W, et al. Additive manufacturing of $\mathrm{ZrO}_{2}-\mathrm{Al}_{2} \mathrm{O}_{3}$ ceramic components by selective laser melting. Rapid Prototyp J 2013, 19: 51-57.

[17] Balla VK, Bose S, Bandyopadhyay A. Processing of bulk alumina ceramics using laser engineered net shaping. Int $J$ Appl Ceram Technol 2008, 5: 234-242.

[18] Liu CY, Xu F, Liu YL, et al. High mass loading ultrathick porous $\mathrm{Li}_{4} \mathrm{Ti}_{5} \mathrm{O}_{12}$ electrodes with improved areal capacity 
fabricated via low temperature direct writing. Electrochimica Acta 2019, 314: 81-88.

[19] Yang LL, Zeng XJ, Ditta A, et al. Preliminary 3D printing of large inclined-shaped alumina ceramic parts by direct ink writing. $J$ Adv Ceram 2020, 9: 312-319.

[20] Chen $\mathrm{AN}, \mathrm{Wu} \mathrm{JM}$, Liu K, et al. High-performance ceramic parts with complex shape prepared by selective laser sintering: A review. Adv Appl Ceram 2018, 117: 100-117.

[21] Zhu ZQ, Gong ZY, Qu P, et al. Additive manufacturing of thin electrolyte layers via inkjet printing of highly-stable ceramic inks. J Adv Ceram 2021, 10: 279-290.

[22] Yang YR, Li L, Zhao J. Mechanical property modeling of photosensitive liquid resin in stereolithography additive manufacturing: Bridging degree of cure with tensile strength and hardness. Mater Des 2019, 162: 418-428.

[23] Roopavath UK, Malferrari S, van Haver A, et al. Optimization of extrusion based ceramic $3 \mathrm{D}$ printing process for complex bony designs. Mater Des 2019, 162: 263-270.

[24] Maleksaeedi S, Eng H, Wiria FE, et al. Property enhancement of 3D-printed alumina ceramics using vacuum infiltration. J Mater Process Technol 2014, 214: 1301-1306.

[25] Tu TZ, Jiang GJ. SiC reticulated porous ceramics by 3D printing, gelcasting and liquid drying. Ceram Int 2018, 44: 3400-3405.

[26] Wozniak M, Graule T, de Hazan Y, et al. Highly loaded UV curable nanosilica dispersions for rapid prototyping applications. J Eur Ceram Soc 2009, 29: 2259-2265.

[27] Chen Z, Li D, Zhou W, et al. Curing characteristics of ceramic stereolithography for an aqueous-based silica suspension. Proc Inst Mech Eng Part B: J Eng Manuf 2010, 224: 641-651.

[28] Luo GQ, Zhang Z, Hu JN, et al. Study on rheological behavior of micro/nano-silicon carbide particles in ethanol by selecting efficient dispersants. Materials 2020, 13: 1496.

[29] Halloran JW. Ceramic stereolithography: Additive manufacturing for ceramics by photopolymerization. Annu Rev Mater Res 2016, 46: 19-40.

[30] Ding GJ, He RJ, Zhang KQ, et al. Dispersion and stability of $\mathrm{SiC}$ ceramic slurry for stereolithography. Ceram Int 2020, 46: 4720-4729.

[31] Ding GJ, He RJ, Zhang KQ, et al. Stereolithographybased additive manufacturing of gray-colored $\mathrm{SiC}$ ceramic green body. J Am Ceram Soc 2019, 102: 7198-7209.

[32] Liu Y, Chen ZW, Li JJ, et al. 3D printing of ceramic cellular structures for potential nuclear fusion application. Addit Manuf 2020, 35: 101348.

[33] Feng CW, Zhang KQ, He RJ, et al. Additive manufacturing of hydroxyapatite bioceramic scaffolds: Dispersion, digital light processing, sintering, mechanical properties, and biocompatibility. J Adv Ceram 2020, 9: 360-373.

[34] Zhang C, Luo ZQ, Liu CB, et al. Dimensional retention of photocured ceramic units during $3 \mathrm{D}$ printing and sintering processes. Ceram Int 2021, 47: 11097-11108.

[35] Chen F, Zhu H, Wu JM, et al. Preparation and biological evaluation of $\mathrm{ZrO}_{2}$ all-ceramic teeth by DLP technology.
Ceram Int 2020, 46: 11268-11274.

[36] Zakeri S, Vippola M, Levänen E. A comprehensive review of the photopolymerization of ceramic resins used in stereolithography. Addit Manuf 2020, 35: 101177.

[37] Lakhdar Y, Tuck C, Binner J, et al. Additive manufacturing of advanced ceramic materials. Prog Mater Sci 2021, 116: 100736 .

[38] Zocca A, Colombo P, Gomes CM, et al. Additive manufacturing of ceramics: Issues, potentialities, and opportunities. J Am Ceram Soc 2015, 98: 1983-2001.

[39] Deckers J, Vleugels J, Kruth J-P. Additive manufacturing of ceramics: A review. Journal of Ceramic Science and Technology 2014, 5: 245-260.

[40] Liu Y, Chen Z. Research progress in photopolymerizationbased 3D printing technology of ceramics. J Mater Eng 2020, 9: 1-12. (in Chinese).

[41] Tomeckova V, Halloran JW. Cure depth for photopolymerization of ceramic suspensions. J Eur Ceram Soc 2010, 30: 3023-3033.

[42] Nowak D, Ortyl J, Kamińska-Borek I, et al. Photopolymerization of hybrid monomers: Part I: Comparison of the performance of selected photoinitiators in cationic and free-radical polymerization of hybrid monomers. Polym Test 2017, 64: 313-320.

[43] Mucci V, Vallo C. Efficiency of 2,2-dimethoxy-2-phenylacetophenone for the photopolymerization of methacrylate monomers in thick sections. J Appl Polym Sci 2012, 123: 418-425.

[44] Tehfe M, Louradour F, Lalevée J, et al. Photopolymerization reactions: On the way to a green and sustainable chemistry. Appl Sci 2013, 3: 490-514.

[45] Fouassier JP, Lalevée J. Photoinitiators for Polymer Synthesis. Weinheim, Germany: Wiley-VCH Verlag GmbH \& Co. KGaA, 2012.

[46] Khudyakov IV. Fast photopolymerization of acrylate coatings: Achievements and problems. Prog Org Coat 2018, 121: 151-159.

[47] Bártolo PJ. Stereolithography: Materials, Processes and Applications. Springer Science \& Business Media, 2011.

[48] Mansfield B, Torres S, Yu T, et al. A review on additive manufacturing of ceramics. In: Proceedings of the ASME 2019 14th International Manufacturing Science and Engineering Conference. Volume 1: Additive Manufacturing; Manufacturing Equipment and Systems; Bio and Sustainable Manufacturing, 2019, Paper No. MSEC2019-2886, V001T01A001

[49] Ferrage L, Bertrand G, Lenormand P, et al. A review of the additive manufacturing (3DP) of bioceramics: Alumina, zirconia (PSZ) and hydroxyapatite. J Aust Ceram Soc 2017, 53: 11-20.

[50] Westbeek S, van Dommelen JAW, Remmers JJC, et al. Multiphysical modeling of the photopolymerization process for additive manufacturing of ceramics. Eur $J$ Mech-A/solids 2018, 71: 210-223.

[51] Diptanshu D, Young E, Ma C, et al. Ceramic additive 
manufacturing using VAT photopolymerization. In: Proceedings of the ASME 2018 13th International Manufacturing Science and Engineering Conference. Volume 1: Additive Manufacturing; Bio and Sustainable Manufacturing, 2018, Paper No. MSEC2018-6389, V001T01A003.

[52] Eren TN, Okte N, Morlet-Savary F, et al. One-component thioxanthone-based polymeric photoinitiators. $J$ Polym Sci Part A: Polym Chem 2016, 54: 3370-3378.

[53] Chartier T, Chaput C, Doreau F, et al. Stereolithography of structural complex ceramic parts. J Mater Sci 2002, 37: 3141-3147.

[54] Lee JH, Prud'homme RK, Aksay IA. Cure depth in photopolymerization: Experiments and theory. $J$ Mater Res 2001, 16: 3536-3544.

[55] Dietliker K, Hüsler R, Birbaum JL, et al. Advancements in photoinitiators-Opening up new applications for radiation curing. Prog Org Coat 2007, 58: 146-157.

[56] Bae CJ, Ramachandran A, Chung $\mathrm{K}$, et al. Ceramic stereolithography: Additive manufacturing for 3D complex ceramic structures. J Korean Ceram Soc 2017, 54: 470-477.

[57] Manapat JZ, Chen QY, Ye PR, et al. 3D printing of polymer nanocomposites via stereolithography. Macromol Mater Eng 2017, 302: 1600553.

[58] Rosental T, Magdassi S. A new approach to 3D printing dense ceramics by ceramic precursor binders. Adv Eng Mater 2019, 21: 1900604.

[59] Li H, Liu YS, Liu YS, et al. Microstructure and properties of 3D-printed alumina ceramics with different heating rates in vacuum debinding. Rare Met 2020, 39: 577-588.

[60] Allen NS. Photoinitiators for UV and visible curing of coatings: Mechanisms and properties. J Photochem Photobiol A: Chem 1996, 100: 101-107.

[61] Komissarenko D, Sokolov P, Evstigneeva A, et al. Rheological and curing behavior of acrylate-based suspensions for the DLP 3D printing of complex zirconia parts. Materials 2018, 11: 2350.

[62] Ligon SC, Liska R, Stampfl J, et al. Polymers for 3D printing and customized additive manufacturing. Chem Rev 2017, 117: 10212-10290.

[63] Sanai Y, Kagami S, Kubota K. Initiation and termination pathways in the photopolymerization of acrylate using methyl phenylglyoxylate as an initiator. Polym J 2020, 52: 375-385.

[64] Andrzejewska E. Photopolymerization kinetics of multifunctional monomers. Prog Polym Sci 2001, 26: 605-665.

[65] Chandra R, Soni RK. Recent developments in thermally curable and photocurable systems. Prog Polym Sci 1994, 19: 137-169.

[66] Linden LA, Paczkowski J, Rabek JF, et al. Photodissociative and electron-transfer photoinitiators of radical polymerization. Polimery 1999, 44: 161-176.

[67] Hageman HJ. Photoinitiators and photoinitiation mechanisms of free-radical polymerisation processes. In: Photopolymerisation and Photoimaging Science and
Technology. Allen NS, Ed. Springer Dordrecht, 1989: $1-53$.

[68] Yang Y, Chen ZY, Song X, et al. Three dimensional printing of high dielectric capacitor using projection based stereolithography method. Nano Energy 2016, 22: 414-421.

[69] De Hazan Y. Porous ceramics, ceramic/polymer, and metal-doped ceramic/polymer nanocomposites via freeze casting of photo-curable colloidal fluids. J Am Ceram Soc 2012, 95: 177-187.

[70] Fu SY, Zhu M, Zhu YF. Organosilicon polymer-derived ceramics: An overview. J Adv Ceram 2019, 8: 457-478.

[71] Eckel ZC, Zhou C, Martin JH, et al. Additive manufacturing of polymer-derived ceramics. Science 2016, 351: 58-62.

[72] Odewale VT. Additive manufacturing of freeform ceramic materials using polymer-derived ceramics (PDC). Florida Agricultural and Mechanical University, 2016.

[73] Wang XF, Schmidt F, Hanaor D, et al. Additive manufacturing of ceramics from preceramic polymers: A versatile stereolithographic approach assisted by thiol-ene click chemistry. Addit Manuf 2019, 27: 80-90.

[74] Hoyle C, Bowman C. Thiol-ene click chemistry. Angew Chem Int Ed 2010, 49: 1540-1573.

[75] Shukla SK, Tiwari RK, Ranjan A, et al. Some thermal studies of polysilanes and polycarbosilanes. Thermochimica Acta 2004, 424: 209-217.

[76] Jones RG, Holder SJ. High-yield controlled syntheses of polysilanes by the Wurtz-type reductive coupling reaction. Polym Int 2006, 55: 711-718.

[77] Li HB, Zhang LT, Cheng LF, et al. Polymer-ceramic conversion of a highly branched liquid polycarbosilane for SiC-based ceramics. J Mater Sci 2008, 43: 2806-2811.

[78] Wang YC, Xiao P, Zhou W, et al. Microstructures, dielectric response and microwave absorption properties of polycarbosilane derived $\mathrm{SiC}$ powders. Ceram Int 2018, 44: 3606-3613.

[79] Hon KKB, Gill TJ. Selective laser sintering of $\mathrm{SiC} /$ polyamide composites. CIRP Ann 2003, 52: 173-176.

[80] Nelson JC, Vail NK, Barlow JW, et al. Selective laser sintering of polymer-coated silicon carbide powders. Ind Eng Chem Res 1995, 34: 1641-1651.

[81] Gardelle B, Duquesne S, Vu C, et al. Thermal degradation and fire performance of polysilazane-based coatings. Thermochimica Acta 2011, 519: 28-37.

[82] Liu G, Zhao Y, Wu G, et al. Origami and 4D printing of elastomer-derived ceramic structures. Sci $A d v$ 2018, 4: eaat0641.

[83] Li S, Duan WY, Zhao T, et al. The fabrication of SiBCN ceramic components from preceramic polymers by digital light processing (DLP) 3D printing technology. $J$ Eur Ceram Soc 2018, 38: 4597-4603.

[84] Obmann R, Schörpf S, Gorsche C, et al. Porous polysilazane-derived ceramic structures generated through photopolymerization-assisted solidification templating. $J$ Eur Ceram Soc 2019, 39: 838-845.

[85] Topa M, Ortyl J. Moving towards a finer way of light- 
cured resin-based restorative dental materials: Recent advances in photoinitiating systems based on iodonium salts. Materials 2020, 13: 4093.

[86] Liew LA, Liu YP, Luo RL, et al. Fabrication of SiCN MEMS by photopolymerization of pre-ceramic polymer. Sensor Actuat A: Phys 2002, 95: 120-134.

[87] Bernardo E, Fiocco L, Parcianello G, et al. Advanced ceramics from preceramic polymers modified at the nano-scale: A review. Materials: Basel 2014, 7: 1927-1956.

[88] Boehm P, Mondeshki M, Frey H. Polysiloxane-backbone block copolymers in a one-pot synthesis: A silicone platform for facile functionalization. Macromol Rapid Commun 2012, 33: 1861-1867.

[89] Chojnowski J, Cypryk M, Kurjata J. Organic polysilanes interrupted by heteroatoms. Prog Polym Sci 2003, 28: 691-728.

[90] Chi FK. Carbon-containing monolithic glasses via the sol-gel process. In: Proceedings of the 7th Annual Conference on Composites and Advanced Ceramic Materials: Ceramic Engineering and Science Proceedings, 1983.

[91] Babonneau F, Thorne K, MacKenzie JD. Dimethyldiethoxysilane/tetraethoxysilane copolymers: Precursors for the silicon-carbon-oxygen system. Chem Mater 1989, 1: 554-558.

[92] Zhang HX, Pantano CG. Synthesis and characterization of silicon oxycarbide glasses. J Am Ceram Soc 1990, 73: 958-963.

[93] Colombo P, Mera G, Riedel R, et al. Polymer-derived ceramics: 40 years of research and innovation in advanced ceramics. J Am Ceram Soc 2010, 93: 1805-1837.

[94] Gervais C, Babonneau F, Dallabonna N, et al. Sol-gelderived silicon-boron oxycarbide glasses containing mixed silicon oxycarbide $\left(\mathrm{SiC}_{x} \mathrm{O}_{4-x}\right)$ and boron oxycarbide $\left(\mathrm{BC}_{y} \mathrm{O}_{3-y}\right)$ units. J Am Ceram Soc 2001, 84: 2160-2164.

[95] Zhou SX, Mei H, Chang P, et al. Molecule editable 3D printed polymer-derived ceramics. Coord Chem Rev 2020, 422: 213486.

[96] Reddy SK, Cramer NB, Cross T, et al. Polymer-derived ceramic materials from thiol-ene photopolymerizations. Chem Mater 2003, 15: 4257-4261.

[97] Mishra MK, Kumar S, Ranjan A, et al. Processing, properties and microstructure of $\mathrm{SiC}$ foam derived from epoxy-modified polycarbosilane. Ceram Int 2018, 44: 1859-1867.

[98] Eick BM, Youngblood JP. SiC nanofibers by pyrolysis of electrospun preceramic polymers. J Mater Sci 2009, 44: 160-165.

[99] Li ZY, Chen ZW, Liu J, et al. Additive manufacturing of lightweight and high-strength polymer-derived SiOC ceramics. Virtual Phys Prototyp 2020, 15: 163-177.

[100] Wang M, Xie C, He RJ, et al. Polymer-derived silicon nitride ceramics by digital light processing based additive manufacturing. J Am Ceram Soc 2019, 102: 5117-5126.

[101] Fu XL, Zhu N, Peng ZJ. One-step synthesis and characterization of tree-like branched $\alpha-\mathrm{Si}_{3} \mathrm{~N}_{4}$ nano/ submicron-structures by pyrolysis of a polymer precursor. Solid State Sci 2012, 14: 1267-1272.

[102] Peng ZJ, Zhu N, Fu XL, et al. Growth and mechanism of network-like branched $\mathrm{Si}_{3} \mathrm{~N}_{4}$ nanostructures. $\mathrm{J} \mathrm{Am} \mathrm{Ceram}$ Soc 2010, 93: 2264-2267.

[103] Zhu N, Peng ZJ, Fu XL, et al. A simple approach to controllably grow network-like branched single-crystalline $\mathrm{Si}_{3} \mathrm{~N}_{4}$ nanostructures. Solid State Sci 2010, 12: 1076-1079.

[104] De Hazan Y, Penner D. SiC and SiOC ceramic articles produced by stereolithography of acrylate modified polycarbosilane systems. J Eur Ceram Soc 2017, 37: 5205-5212.

[105] Chen HH, Wang XF, Xue FD, et al. 3D printing of SiC ceramic: Direct ink writing with a solution of preceramic polymers. J Eur Ceram Soc 2018, 38: 5294-5300.

[106] Xu XB, Li PY, Ge CH, et al. 3D printing of complex-type SiOC ceramics derived from liquid photosensitive resin. ChemistrySelect 2019, 4: 6862-6869.

[107] Brinckmann SA, Patra N, Yao J, et al. Stereolithography of SiOC polymer-derived ceramics filled with $\mathrm{SiC}$ micronwhiskers. Adv Eng Mater 2018, 20: 1800593.

[108] Zanchetta E, Cattaldo M, Franchin G, et al. Stereolithography of SiOC ceramic microcomponents. Adv Mater 2016, 28 : 370-376.

[109] Fu YL, Xu G, Chen ZW, et al. Multiple metals doped polymer-derived SiOC ceramics for 3D printing. Ceram Int 2018, 44: 11030-11038.

[110] Zocca A, Gomes CM, Staude A, et al. SiOC ceramics with ordered porosity by $3 \mathrm{D}$-printing of a preceramic polymer. $J$ Mater Res 2013, 28: 2243-2252.

[111] Huang K, Elsayed H, Franchin G, et al. 3D printing of polymer-derived SiOC with hierarchical and tunable porosity. Addit Manuf 2020, 36: 101549.

[112] Kulkarni A, Sorarù GD, Pearce JM. Polymer-derived SiOC replica of material extrusion-based 3-D printed plastics. Addit Manuf 2020, 32: 100988.

[113] He C, Ma C, Li XL, et al. Polymer-derived SiOC ceramic lattice with thick struts prepared by digital light processing. Addit Manuf 2020, 35: 101366.

[114] Zhang CY, Han KQ, Liu Y, et al. A novel high yield polyborosilazane precursor for SiBNC ceramic fibers. Ceram Int 2017, 43: 10576-10580.

[115] Zhang Q, Yang ZH, Jia DC, et al. Synthesis and structural evolution of dual-boron-source-modified polysilazane derived SiBCN ceramics. New J Chem 2016, 40: 7034-7042.

[116] He WQ, Chen LX, Peng F. Coating formed by SiBCN single source precursor via UV-photopolymerization. Mater Lett 2017, 206: 121-123.

[117] He WQ, Chen LX, Xu TT, et al. Synthesis of borosilazane as UV-curable borazine-type single source precursor for SiBCN ceramic materials. Ceram Int 2015, 41: 10448 10455 .

[118] Wang JC, Dommati H, Hsieh SJ. Review of additive manufacturing methods for high-performance ceramic materials. Int J Adv Manuf Technol 2019, 103: 2627-2647. 
[119] Melisaris AP, Renyi W, Pang TH. Liquid, radiationcurable composition, especially for producing flexible cured articles by stereolithography. Google Patents, 2000.

[120] Wu LF, Zhao LD, Jian M, et al. EHMP-DLP: Multiprojector DLP with energy homogenization for large-size 3D printing. Rapid Prototyp J 2018, 24: 1500-1510.

[121] Fiedor P, Ortyl J. A new approach to micromachining: High-precision and innovative additive manufacturing solutions based on photopolymerization technology. Materials 2020, 13: 2951.

[122] Zhou WZ, Li DC, Chen ZW. The influence of ingredients of silica suspensions and laser exposure on UV curing behavior of aqueous ceramic suspensions in stereolithography. Int J Adv Manuf Technol 2011, 52: 575-582.

[123] Tian XY, Li DC, Chen ZW, et al. Study on the fabrication accuracy of ceramic parts by direct stereolithography. Virtual Phys Prototyp 2012, 7: 195-202.

[124] Zaheer M, Schmalz T, Motz G, et al. Polymer derived non-oxide ceramics modified with late transition metals. Chem Soc Rev 2012, 41: 5102-5116.

[125] Corcione CE, Greco A, Montagna F, et al. Silica moulds built by stereolithography. J Mater Sci 2005, 40: 4899-4904.

[126] Chartier T, Badev A, Abouliatim Y, et al. Stereolithography process: Influence of the rheology of silica suspensions and of the medium on polymerization kinetics - Cured depth and width. J Eur Ceram Soc 2012, 32: 1625-1634.

[127] Bae CJ, Halloran JW. Integrally cored ceramic mold fabricated by ceramic stereolithography. Int J Appl Ceram Technol 2011, 8: 1255-1262.

[128] Singh P, Smith LS, Bezdecny M, et al. Additive manufacturing of PZT-5H piezoceramic for ultrasound transducers. In: Proceedings of the 2011 IEEE International Ultrasonics Symposium, 2011: 1111-1114.

[129] Chen Y, Bao XL, Wong CM, et al. PZT ceramics fabricated based on stereolithography for an ultrasound transducer array application. Ceram Int 2018, 44: 22725-22730.

[130] Dufaud O, Marchal P, Corbel S. Rheological properties of PZT suspensions for stereolithography. J Eur Ceram Soc 2002, 22: 2081-2092.

[131] Chartier T, Dupas C, Geffroy PM, et al. Influence of irradiation parameters on the polymerization of ceramic reactive suspensions for stereolithography. $J$ Eur Ceram Soc 2017, 37: 4431-4436.

[132] Yuan J, Li X, Qi Y, et al. Enhanced digital light processing-based mask projection stereolithography method and apparatus. Google Patents, 2016.

[133] Ertugrul I. The fabrication of micro beam from photopolymer by digital light processing 3D printing technology. Micromachines 2020, 11: 518.

[134] Rahman MM. Statistical analysis of the digital micromirror devices hinge sag phenomenon. Master Thesis. Texas Tech University, 2002.

[135] Schmidt J, Elsayed H, Bernardo E, et al. Digital light processing of wollastonite-diopside glass-ceramic complex structures. J Eur Ceram Soc 2018, 38: 4580-4584.
[136] He L, Song X. Supportability of a high-yield-stress slurry in a new stereolithography-based ceramic fabrication process. JOM 2018, 70: 407-412.

[137] Fu YL, Chen ZW, Xu G, et al. Preparation and stereolithography $3 \mathrm{D}$ printing of ultralight and ultrastrong $\mathrm{ZrOC}$ porous ceramics. J Alloys Compd 2019, 789: 867-873.

[138] Sun JX, Binner J, Bai JM. Effect of surface treatment on the dispersion of nano zirconia particles in non-aqueous suspensions for stereolithography. J Eur Ceram Soc 2019, 39: $1660-1667$

[139] Zhang KQ, He RJ, Xie C, et al. Photosensitive $\mathrm{ZrO}_{2}$ suspensions for stereolithography. Ceram Int 2019, 45: 12189-12195.

[140] Lian Q, Sui WQ, Wu XQ, et al. Additive manufacturing of $\mathrm{ZrO}_{2}$ ceramic dental bridges by stereolithography. Rapid Prototyp J 2018, 24: 114-119.

[141] Li XY, Hu KH, Lu ZG. Effect of light attenuation on polymerization of ceramic suspensions for stereolithography. J Eur Ceram Soc 2019, 39: 2503-2509.

[142] Wu XQ, Lian Q, Li DC, et al. Influence of boundary masks on dimensions and surface roughness using segmented exposure in ceramic 3D printing. Ceram Int 2019, 45: 3687-3697.

[143] Hu KH, Wei YM, Lu ZG, et al. Design of a shaping system for stereolithography with high solid loading ceramic suspensions. 3D Print Addit Manuf 2018, 5: 311-318.

[144] Jang KJ, Kang JH, Fisher JG, et al. Effect of the volume fraction of zirconia suspensions on the microstructure and physical properties of products produced by additive manufacturing. Dent Mater 2019, 35: e97-e106.

[145] Huang RJ, Jiang QG, Wu HD, et al. Fabrication of complex shaped ceramic parts with surface-oxidized $\mathrm{Si}_{3} \mathrm{~N}_{4}$ powder via digital light processing based stereolithography method. Ceram Int 2019, 45: 5158-5162.

[146] Li F, Ji X, Wu ZX, et al. Digital light processing 3D printing of ceramic shell for precision casting. Mater Lett 2020, 276: 128037.

[147] Chen ZW, Liu CB, Li JJ, et al. Mechanical properties and microstructures of 3D printed bulk cordierite parts. Ceram Int 2019, 45: 19257-19267.

[148] Santoliquido O, Colombo P, Ortona A. Additive manufacturing of ceramic components by Digital Light Processing: A comparison between the "bottom-up" and the "top-down" approaches. J Eur Ceram Soc 2019, 39: 2140-2148.

[149] Schmidt J, Colombo P. Digital light processing of ceramic components from polysiloxanes. J Eur Ceram Soc 2018, 38: $57-66$.

[150] Shuai XG, Zeng Y, Li PR, et al. Fabrication of fine and complex lattice structure $\mathrm{Al}_{2} \mathrm{O}_{3}$ ceramic by digital light processing 3D printing technology. J Mater Sci 2020, 55: 6771-6782.

[151] Shukrun E, Cooperstein I, Magdassi S. 3D-printed organicceramic complex hybrid structures with high silica content. Adv Sci 2018, 5: 1800061. 
[152] Gyak KW, Vishwakarma NK, Hwang YH, et al. 3Dprinted monolithic $\mathrm{SiCN}$ ceramic microreactors from a photocurable preceramic resin for the high temperature ammonia cracking process. React Chem Eng 2019, 4: 1393-1399.

[153] Varadan VK, Jiang X, Varadan VV. Microstereolithography and Other Fabrication Techniques for 3D MEMS. New York (USA): John Wiley \& Sons Inc, 2001.

[154] Schizas C, Melissinaki V, Gaidukeviciute A, et al. On the design and fabrication by two-photon polymerization of a readily assembled micro-valve. Int $J$ Adv Manuf Technol 2010, 48: 435-441.

[155] Seet K, Mizeikis V, Matsuo S, et al. Three-dimensional spiral-architecture photonic crystals obtained by direct laser writing. Adv Mater 2005, 17: 541-545.

[156] Xing JF, Zheng ML, Duan XM. Two-photon polymerization microfabrication of hydrogels: An advanced 3D printing technology for tissue engineering and drug delivery. Chem Soc Rev 2015, 44: 5031-5039.

[157] Zhou XQ, Hou YH, Lin JQ. A review on the processing accuracy of two-photon polymerization. $A I P A d v 2015,5$ : 030701.

[158] Brigo L, Schmidt JEM, Gandin A, et al. 3D nanofabrication of SiOC ceramic structures. Adv Sci 2018, 5: 1800937.

[159] Tétreault N, von Freymann G, Deubel M, et al. New route to three-dimensional photonic bandgap materials: Silicon double inversion of polymer templates. Adv Mater 2006, 18: $457-460$

[160] Meza LR, Greer JR. Mechanical characterization of hollow ceramic nanolattices. J Mater Sci 2014, 49: 2496-2508.

[161] Jang D, Meza LR, Greer F, et al. Fabrication and deformation of three-dimensional hollow ceramic nanostructures. Nat Mater 2013, 12: 893-898.

[162] Wang ZJ, Martin N, Hini D, et al. Rapid fabrication of multilayer microfluidic devices using the liquid crystal display-based stereolithography 3D printing system. 3D Print Addit Manuf 2017, 4: 156-164.

[163] Tosto C, Pergolizzi E, Blanco I, et al. Epoxy based blends for additive manufacturing by liquid crystal display (LCD) printing: The effect of blending and dual curing on daylight curable resins. Polymers 2020, 12: 1594.

[164] Shan JY, Yang ZJ, Chen GG, et al. Design and synthesis of free-radical/cationic photosensitive resin applied for $3 \mathrm{D}$ printer with liquid crystal display (LCD) irradiation. Polymers 2020, 12: 1346.

[165] Janusziewicz R, Tumbleston JR, Quintanilla AL, et al. Layerless fabrication with continuous liquid interface production. PNAS 2016, 113: 11703-11708.

[166] Xu J, Jung K, Atme A, et al. A robust and versatile photoinduced living polymerization of conjugated and unconjugated monomers and its oxygen tolerance. $J \mathrm{Am}$ Chem Soc 2014, 136: 5508-5519.

[167] Travitzky N, Bonet A, Dermeik B, et al. Additive manufacturing of ceramic-based materials. Adv Eng
Mater 2014, 16: 729-754.

[168] Yang C, Wang XY, Ma B, et al. 3D-printed bioactive $\mathrm{Ca}_{3} \mathrm{SiO}_{5}$ bone cement scaffolds with nano surface structure for bone regeneration. ACS Appl Mater Interfaces 2017, 9: 5757-5767.

[169] Lin K, Sheikh R, Romanazzo S, et al. 3D printing of bioceramic scaffolds-Barriers to the clinical translation: From promise to reality, and future perspectives. Materials 2019, 12: 2660.

[170] Badev A, Abouliatim Y, Chartier T, et al. Photopolymerization kinetics of a polyether acrylate in the presence of ceramic fillers used in stereolithography. $J$ Photochem Photobiol A: Chem 2011, 222: 117-122.

[171] Zhou WZ, Li D, Chen ZW, et al. Direct fabrication of an integral ceramic mould by stereolithography. Proc Inst Mech Eng Part B J Eng Manuf 2010, 224: 237-243.

[172] Scalera F, Esposito Corcione C, Montagna F, et al. Development and characterization of UV curable epoxy/ hydroxyapatite suspensions for stereolithography applied to bone tissue engineering. Ceram Int 2014, 40: 15455-15462.

[173] Du D, Asaoka T, Ushida T, et al. Fabrication and perfusion culture of anatomically shaped artificial bone using stereolithography. Biofabrication 2014, 6: 045002.

[174] Nguyen NT, Delhote N, Ettorre M, et al. Design and characterization of $60-\mathrm{GHz}$ integrated lens antennas fabricated through ceramic stereolithography. IEEE Trans Antennas Propag 2010, 58: 2757-2762.

[175] Chen W, Kirihara S, Miyamoto Y. Fabrication and measurement of micro three-dimensional photonic crystals of $\mathrm{SiO}_{2}$ ceramic for terahertz wave applications. $J \mathrm{Am}$ Ceram Soc 2007, 90: 2078-2081.

[176] Kirihara S, Niki T. Three-dimensional stereolithography of alumina photonic crystals for terahertz wave localization. Int J Appl Ceram Technol 2015, 12: 32-37.

[177] Scheithauer U, Schwarzer E, Moritz T, et al. Additive manufacturing of ceramic heat exchanger: Opportunities and limits of the lithography-based ceramic manufacturing (LCM). J Mater Eng Perform 2018, 27: 14-20.

[178] Koroleva A, Deiwick A, Nguyen A, et al. Osteogenic differentiation of human mesenchymal stem cells in 3-D $\mathrm{Zr}$-Si organic-inorganic scaffolds produced by two-photon polymerization technique. PLOS ONE 2015, 10: e0118164.

[179] Meza LR, Das S, Greer JR. Strong, lightweight, and recoverable three-dimensional ceramic nanolattices. Science 2014, 345: 1322-1326.

[180] Cumpston BH, Ananthavel SP, Barlow S, et al. Two-photon polymerization initiators for three-dimensional optical data storage and microfabrication. Nature 1999, 398: 51.

[181] Sun H-B, Matsuo S, Misawa H. Three-dimensional photonic crystal structures achieved with two-photonabsorption photopolymerization of resin. Appl Phys Lett 1999, 74: 786-788.

[182] Pham TA, Kim DP, Lim TW, et al. Three-dimensional $\mathrm{SiCN}$ ceramic microstructures via nano-stereolithography of inorganic polymer photoresists. Adv Funct Mater 2006, 
16: $1235-1241$.

[183] Mei H, Huang W, Liu H, et al. 3D printed carbon-ceramic structures for enhancing photocatalytic properties. Ceram Int 2019, 45: 15223-15229.

[184] Duan X-M, Sun H-B, Kaneko K, et al. Two-photon polymerization of metal ions doped acrylate monomers and oligomers for three-dimensional structure fabrication. Thin Solid Films 2004, 453: 518-521.

[185] Hong H, Seo YB, Lee JS, et al. Digital light processing 3D printed silk fibroin hydrogel for cartilage tissue engineering. Biomaterials 2020, 232: 119679.

[186] Raja N, Yun H-s. A simultaneous 3D printing process for the fabrication of bioceramic and cell-laden hydrogel core/shell scaffolds with potential application in bone tissue regeneration. J Mater Chem B 2016, 4: 4707-4716.
Open Access This article is licensed under a Creative Commons Attribution 4.0 International License, which permits use, sharing, adaptation, distribution and reproduction in any medium or format, as long as you give appropriate credit to the original author(s) and the source, provide a link to the Creative Commons licence, and indicate if changes were made.

The images or other third party material in this article are included in the article's Creative Commons licence, unless indicated otherwise in a credit line to the material. If material is not included in the article's Creative Commons licence and your intended use is not permitted by statutory regulation or exceeds the permitted use, you will need to obtain permission directly from the copyright holder.

To view a copy of this licence, visit http://creativecommons.org/licenses/by/4.0/. 